\title{
The GEWEX LandFlux project: evaluation of model evaporation using tower-based and globally gridded forcing data
}

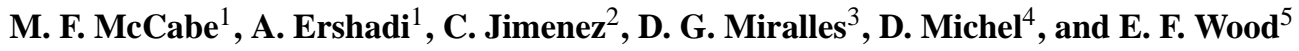 \\ ${ }^{1}$ Division of Biological and Environmental Sciences and Engineering, King Abdullah University \\ of Science and Technology, Thuwal, Saudi Arabia \\ ${ }^{2}$ Estellus, Paris, France \\ ${ }^{3}$ Department of Earth Sciences, VU University Amsterdam, Amsterdam, the Netherlands \\ ${ }^{4}$ Institute for Atmospheric and Climate Sciences, ETH Zurich, Zurich, Switzerland \\ ${ }^{5}$ Department of Civil and Environmental Engineering, Princeton University, Princeton, NJ, USA \\ Correspondence to: M. F. McCabe (matthew.mccabe@kaust.edu.sa)
}

Received: 2 July 2015 - Published in Geosci. Model Dev. Discuss.: 24 August 2015

Revised: 5 January 2016 - Accepted: 6 January 2016 - Published: 26 January 2016

\begin{abstract}
Determining the spatial distribution and temporal development of evaporation at regional and global scales is required to improve our understanding of the coupled water and energy cycles and to better monitor any changes in observed trends and variability of linked hydrological processes. With recent international efforts guiding the development of long-term and globally distributed flux estimates, continued product assessments are required to inform upon the selection of suitable model structures and also to establish the appropriateness of these multi-model simulations for global application. In support of the objectives of the Global Energy and Water Cycle Exchanges (GEWEX) LandFlux project, four commonly used evaporation models are evaluated against data from tower-based eddy-covariance observations, distributed across a range of biomes and climate zones. The selected schemes include the Surface Energy Balance System (SEBS) approach, the Priestley-Taylor Jet Propulsion Laboratory (PT-JPL) model, the PenmanMonteith-based $\mathrm{Mu}$ model (PM-Mu) and the Global Land Evaporation Amsterdam Model (GLEAM). Here we seek to examine the fidelity of global evaporation simulations by examining the multi-model response to varying sources of forcing data. To do this, we perform parallel and collocated model simulations using tower-based data together with a global-scale grid-based forcing product. Through quantifying the multi-model response to high-quality tower data, a better understanding of the subsequent model response to the coarse-scale globally gridded data that underlies the Land-
\end{abstract}

Flux product can be obtained, while also providing a relative evaluation and assessment of model performance.

Using surface flux observations from 45 globally distributed eddy-covariance stations as independent metrics of performance, the tower-based analysis indicated that PTJPL provided the highest overall statistical performance $\left(0.72 ; 61 \mathrm{~W} \mathrm{~m}^{-2} ; 0.65\right)$, followed closely by GLEAM $(0.68$; $64 \mathrm{~W} \mathrm{~m}^{-2}$; 0.62), with values in parentheses representing the $R^{2}$, RMSD and Nash-Sutcliffe efficiency (NSE), respectively. PM-Mu $\left(0.51 ; 78 \mathrm{~W} \mathrm{~m}^{-2} ; 0.45\right)$ tended to underestimate fluxes, while SEBS $\left(0.72 ; 101 \mathrm{~W} \mathrm{~m}^{-2} ; 0.24\right)$ overestimated values relative to observations. A focused analysis across specific biome types and climate zones showed considerable variability in the performance of all models, with no single model consistently able to outperform any other. Results also indicated that the global gridded data tended to reduce the performance for all of the studied models when compared to the tower data, likely a response to scale mismatch and issues related to forcing quality. Rather than relying on any single model simulation, the spatial and temporal variability at both the tower- and grid-scale highlighted the potential benefits of developing an ensemble or blended evaporation product for global-scale LandFlux applications. Challenges related to the robust assessment of the LandFlux product are also discussed. 


\section{Introduction}

Characterizing the exchange of water between the land surface and the atmosphere is a topic of multi-disciplinary interest, as the processes that comprise this dynamic cycling of water determine the spatial and temporal variability of hydrological responses across local and global scales. In recent years, there has been significant progress in the development of regional and global data sets based largely on remote sensing retrievals. These data have provided a wealth of spatially and temporally varying information across a range of Earth system processes, including soil moisture (Liu et al., 2011a), vegetation change (Tucker et al., 2005; Liu et al., 2011b, 2013), groundwater (Famiglietti et al., 2011; Richey et al., 2015) and precipitation (Huffman et al., 1995; Nesbitt et al., 2004), enabling a capacity to enhance our understanding and description of regional- and global-scale water cycles and their spatial and temporal variability. While evaporation represents the key process returning the Earth's surface water to the overlying atmosphere and provides the linking mechanism between the water and energy cycles, it is only in relatively recent times that effort has been directed towards the development of global products (Mu et al., 2007; Fisher et al., 2008; Vinukollu et al., 2011a).

To address this observation limitation, a number of evaporation modelling approaches have been developed over the past few years to enable estimation at scales beyond the field, using satellite remote sensing (Sheffield et al., 2010; Miralles et al., 2011a) and other data sources (Douville et al., 2013). The models tend to differ in their level of empiricism and in the desired scale of application, with some exclusively developed for farm-scale operation and requiring local calibration (Bastiaanssen et al., 1998; Allen et al., 2007). Others have been developed for broader-scale application and are built on physical relationships describing the water and energy transfer at the land surface (Norman et al., 1995; Su, 2002; Fisher et al., 2008; Miralles et al., 2011a). While traditional applications of evaporation estimates have been directed towards agricultural monitoring (Allen, 2000), catchment water budgets and basin-scale water management (Kustas et al., 1994; Granger, 2000), more recent applications of evaporation products have included detection and prediction of heatwaves (Hirschi et al., 2011; Miralles et al., 2014a), droughts (Mu et al., 2012; Otkin et al., 2014) and in resolving the likely contribution of human-induced climate change on such events (Greve et al., 2014).

Despite the importance of understanding the magnitude and spatial and temporal variability of evaporation, the availability of long-term products required to do this are rather limited. Characterizing the long-term trends and variability in independent observations of the Earth's coupled water and energy cycles is a key objective of the World Climate Research Programmes (WCRP) Global Energy and Water Cycle Exchanges (GEWEX) project. Towards this task, the GEWEX Data and Assessments Panels (GDAP) Land-
Flux project has coordinated two interrelated research efforts that seek to (i) intercompare long-term gridded surface flux data sets and identify their skill and reliability (i.e. productbenchmarking), and (ii) simulate and intercompare evaporation models to identify algorithms appropriate for developing a global flux product (i.e. model-benchmarking). In one of the first global-scale product assessments, Jiménez et al. (2011) examined 12 evaporation products obtained from satellite-based, reanalyses and offline land surface model (LSM) simulations for a 3-year period (1993-1995), identifying large correlations between the products, similarity in their spatial distributions, as well as large absolute differences in the annual average evaporation. A complementary investigation of the inter-product differences was undertaken by Mueller et al. (2011), which included forty-one global evaporation data sets across a range of satellite-based simulations, LSMs, global circulation models (GCMs), atmospheric reanalyses data sets, empirical up-scaling of eddycovariance measurements, as well as atmospheric water budget data sets. In that study, Mueller et al. (2011) used 7 years of monthly mean data for the period 1989-1995 and found strong similarity in the absolute magnitude and spatial distribution of evaporation amongst the products. More recently, Mueller et al. (2013) examined multi-annual trends and variations in evaporation products from a range of diagnostic data sets, LSMs and reanalysis products and showed consistency in inter-annual variations of evaporation products that corresponded well with previous investigations (Jung et al., 2010).

These benchmarking studies provided a thorough (and much needed) assessment of available global evaporation products and the varying approaches used to derive them. However, evaluation of the models for their predictive skill was challenging due to inconsistencies in the forcing data used to drive the models, as well as to the different parameterisation schemes employed. That is, the analysis was performed on the published evaporation output, rather than rerunning simulations from a common forcing data set. In these benchmarking studies, the evaporation data sets were also aggregated to similar spatial and temporal resolutions for a common analysis period, to enable unbiased comparison. Uncertainties emerging from such aggregations can often reduce the confidence in any subsequent model performance ranking. One initial effort addressing this was the study of Vinukollu et al. (2011a), which used the Surface Energy Balance System (SEBS) model (SEBS; Su, 2002), a twosource Penman-Monteith scheme by Mu et al. (2007) and a three-source model based on parameterising the PriestleyTaylor model (PT-JPL) (Fisher et al., 2008) to estimate global evaporation for the period 2003-2004. The Vinukollu et al. (2011a) analysis revealed that the modelled instantaneous evaporation (coinciding with the time of satellite overpass) was in reasonable agreement with locally observed evaporation at 12 eddy-covariance towers across the United States, with correlations ranging from 0.43 to 0.54 . However, uncer- 
tainties resulting from scale mismatch between satellite data and the validation tower footprint reduced the confidence and skill ranking of the models. One of the unique aspects of the present study is that tower data are consistent across all model simulations; that is, tower-bias is minimised, by ensuring that all models are assessed against the same tower records. Further, even though sub-grid-scale variability is not explored here (since none of the models explicitly account for this), the tower-to-grid-scale analysis acts as a diagnostic of representativeness and point-to-pixel error.

Recently, Ershadi et al. (2014) examined a number of models including SEBS, PT-JPL, the advection-aridity model of Brutsaert and Stricker (1979) and a single-source PenmanMonteith (PM) model (Monteith, 1965), using a set of 20 flux towers distributed across a range of biome types and climate zones to force the models with tower-based data directly. Based on common forcing and considering overall results, the study found that PT-JPL was the best performing model, followed by SEBS, PM and advection-aridity. In a related contribution, Ershadi et al. (2015) provided a more focused analysis on the influence of model structure and resistance parameterisation on single, two-layer and three-source Penman-Monteith models. The authors identified considerable variability in the performance of models due to their structure and parameterisation choices. While establishing a baseline level of performance at the tower scale is important, understanding the impact of using the large-scale globally gridded forcing that will ultimately drive the global products is key. Indeed, undertaking a parallel assessment between the tower and grid scales, while imposing consistency in the forcing data and sampling locations used, allows for a much greater understanding of model response than can be achieved through either assessment in isolation: an important extension upon recent tower-only analyses, such as Ershadi et al. (2014) and related contributions.

A parallel effort to the LandFlux project is the European Space Agency (ESA) funded Water Cycle Multi-mission Observation Strategy for Evapotranspiration (WACMOS-ET; see http://wacmoset.estellus.eu/). WACMOS-ET, which is focused on an analysis period covering 2005-2007, seeks to better understand the impacts of model structure on flux estimation, with an additional focus on developing a consistent forcing data set using predominantly ESA developed products. A key result from these early works and the preliminary outcomes from WACMOS-ET support the finding that no single model or parameterisation consistently outperformed any other across different biomes. Further details on these complimentary efforts can be found in Michel et al. (2015) and Miralles et al. (2015).

The focus of the current investigation is to build upon these recent efforts as well as to complement ongoing WACMOSET investigations, by simulating state-of-the-art evaporation models using a joint assessment of tower-based and gridded data, and comparing results with available eddy-covariance flux observations. Understanding how application of grid- ded forcing data might influence the performance of the selected models, relative to their performance when forced with (presumably) higher-quality tower data, is a motivating rationale for this work. Such evaluations are important as they offer insight into the sensitivity of the models to input data uncertainties, provide a relative assessment of model quality and also inform upon issues of spatial scale and footprint mismatch (McCabe and Wood, 2006). Establishing model suitability for large-scale operational application as part of the GEWEX LandFlux project is a further motivating goal for this work. As such, a major objective is to evaluate the individual model responses across a large range of biomes and climate zones. The models selected for assessment include SEBS, PT-JPL, the Penman-Monteith-based Mu model (PM-Mu) (Mu et al., 2011) as well as the Global Land Evaporation Amsterdam Methodology (GLEAM) (Miralles et al., 2011a). These models satisfy a number of criteria that were considered important for global model selection, including reliance on a minimum number of forcing variables, capacity to use remote-sensing-based observations, as well as previous application at either the regional or global scale.

\section{Data and methodology}

\subsection{Data}

For this analysis, model simulations cover the period from 1997 to 2007 and are performed at a 3-hourly temporal resolution. To examine model response and inter-product variability, a parallel tower- and grid-based analysis was performed. Data for the tower-based analysis are derived from a set of 45 eddy-covariance towers (see Table A1), while the gridded data are extracted from a compilation of available globally distributed satellite, meteorological and land surface characteristics products. Compared to the 0.5 degree and 3-hourly gridded data, the use of tower-based forcing is expected to minimise issues related to footprint uncertainties when evaluating simulations against the observed eddycovariance-based flux data. The primary purpose of the gridbased analysis is to better understand the effects of largescale forcing data on the accuracy of global retrievals, relative to the tower-based evaluations.

\subsubsection{Description of tower-based forcing data}

Data for the tower-based analyses are derived from forty-five eddy-covariance towers selected from within the FLUXNET database (Baldocchi et al., 2001). Table A1 lists the key attributes of the selected towers and Fig. A1 describes the varying temporal lengths of the tower records used in this study. The requirement that towers only be used if they are able to provide the input data required by all models (see Table 1) was a strong limiting criterion that significantly reduced the number of available study sites. In particular, the availability 
Table 1. Summary of data sources for tower-based and grid-based analysis and their spatial and temporal resolutions.

\begin{tabular}{|c|c|c|c|}
\hline Variable & Tower-based & Grid-based & Model \\
\hline Air temperature & Tower data aggregated to 3-hourly & LandFlux data at $0.5^{\circ}$ and 3-hourly & All models \\
\hline Humidity & $\begin{array}{l}\text { Tower-based relative humidity } \\
\text { converted to specific humidity and } \\
\text { aggregated to 3-hourly }\end{array}$ & $\begin{array}{l}\text { Specific humidity from LandFlux data } \\
\text { at } 0.5^{\circ} \text { and 3-hourly }\end{array}$ & All except GLEAM \\
\hline Pressure & $\begin{array}{l}\text { Calculated as a function of ground } \\
\text { elevation }\end{array}$ & LandFlux data at $0.5^{\circ}$ and 3-hourly & All models \\
\hline Net radiation & Tower data aggregated to 3-hourly & $\begin{array}{l}\text { LandFlux data from SRB v3 at } 1^{\circ} \text { and } \\
\text { 3-hourly }\end{array}$ & All models \\
\hline Ground heat flux & Tower data aggregated to 3-hourly & $\begin{array}{l}\text { Calculated from net radiation and } \\
\text { fractional vegetation cover data, } 0.5^{\circ} \\
\text { and 3-hourly }\end{array}$ & All models \\
\hline $\begin{array}{l}\text { Land surface } \\
\text { temperature }\end{array}$ & $\begin{array}{l}\text { Calculated from tower-based longwave } \\
\text { upward radiation and aggregated to } \\
\text { 3-hourly }\end{array}$ & LandFlux data at $0.5^{\circ}$ and 3-hourly & SEBS only \\
\hline Wind speed & Tower data aggregated to 3-hourly & LandFlux data at $0.5^{\circ}$ and 3-hourly & SEBS only \\
\hline Canopy height & Tower metadata & Simard et al. (2011) product and Eq. (1) & SEBS only \\
\hline NDVI & GIMMS NDVI at $8 \mathrm{~km}$ and bi-monthly & GIMMS NDVI at $0.5^{\circ}$ and bi-monthly & All except GLEAM \\
\hline Leaf area index & Calculated from NDVI & LandFlux data at $0.5^{\circ}$ and monthly & SEBS and PM-Mu \\
\hline $\begin{array}{l}\text { Fractional vegetation } \\
\text { cover }\end{array}$ & Calculated from NDVI & Calculated from NDVI & All except GLEAM \\
\hline Precipitation & Tower data aggregated to 3-hourly & LandFlux data at $0.5^{\circ}$ and 3-hourly & GLEAM only \\
\hline Soil properties & IGBP-DIS at 5 arcmin & IGBP-DIS data aggregated to $0.5^{\circ}$ & GLEAM only \\
\hline Soil moisture & CCI-WACMOS data at $0.25^{\circ}$ and daily & Same as tower-based & GLEAM only \\
\hline Soil depth & GlobSnow (daily and $25 \mathrm{~km}$ ) & Same as tower-based & GLEAM only \\
\hline $\begin{array}{l}\text { Vegetation optical } \\
\text { depth }\end{array}$ & $\begin{array}{l}\text { From Liu et al. (2011b) at } 0.25^{\circ} \text { and } \\
\text { daily }\end{array}$ & Same as tower-based & GLEAM only \\
\hline Snow water equivalent & $\begin{array}{l}\text { GlobSnow and NSIDC at } 0.25^{\circ} \text { and } \\
\text { daily }\end{array}$ & Same as tower-based & GLEAM only \\
\hline Lightning frequency & Monthly climatology at $0.5^{\circ}$ & Same as tower-based & GLEAM only \\
\hline Cover fractions & MOD44B data at $250 \mathrm{~m}$ & MOD44B data at $0.5^{\circ}$ & GLEAM only \\
\hline
\end{tabular}

of land surface temperature data, which is required for SEBS, drastically constrained the choice of towers. However, ensuring data consistency within the towers used for simulation and assessment was an important component of this work, as it removes the impact of tower bias in subsequent model assessment. Even with this reduced number, the selected towers represent a considerable spatial spread encompassing a variety of biome types and climate zones (see Fig. 1).

In terms of forcing data requirements, tower-based variables that were used for model simulations include air temperature, relative humidity, wind speed, net radiation, ground heat flux and precipitation. A summary of the forcing data requirements for each model is provided in Table 1. Land surface emissivity, leaf area index and fractional vegetation cover were estimated from normalized difference vegetation index (NDVI) data obtained from the Global Inventory Monitoring and Modelling Study (GIMMS) data set (Tucker et al., 2005), at $8 \mathrm{~km}$ spatial and bi-monthly temporal resolutions. Here, the emissivity was calculated using the approach of Sobrino et al. (2004), leaf area index was estimated following Fisher et al. (2008) and the fractional vegetation cover was estimated using the technique described in Jiménez-Muñoz et al. (2009). Land surface temperature was calculated using tower-observed longwave upward radiation and by invert- 


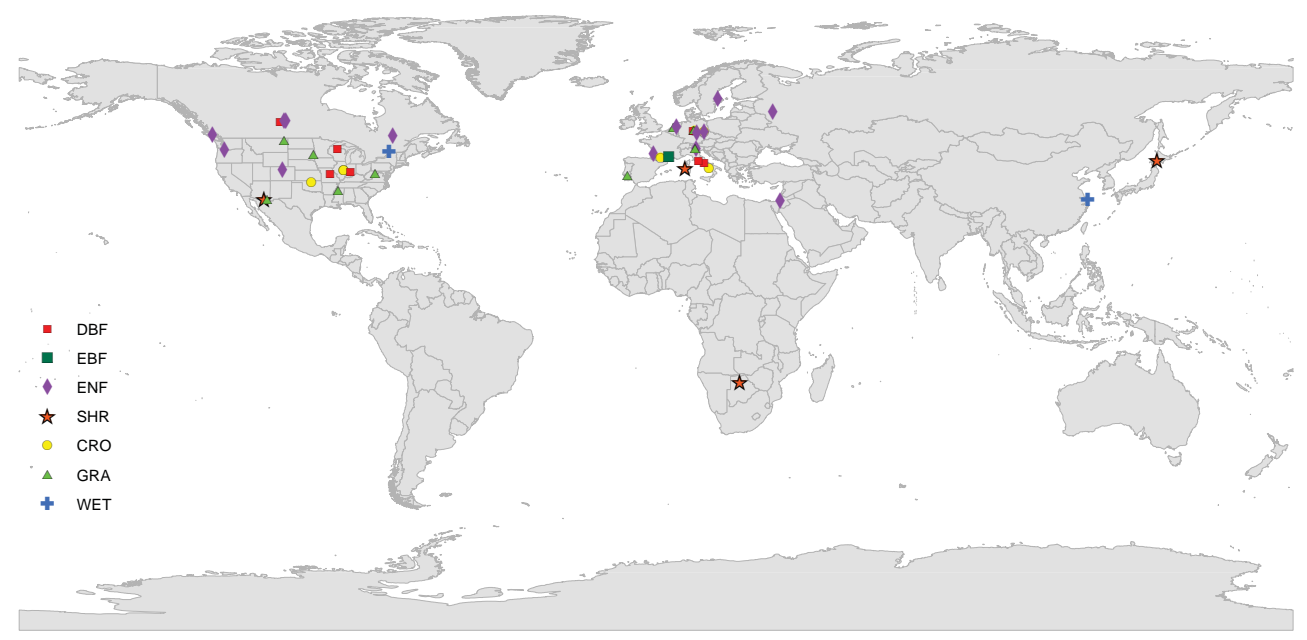

Figure 1. Location of the selected towers and their distributions for various biomes.

ing the Stefan-Boltzmann equation (Brutsaert, 2005). Atmospheric pressure data, which are absent from many towers, were calculated based on ground elevation of tower locations using an equation presented in Bos et al. (2008). Canopy height $\left(h_{\mathrm{c}}\right)$, which is needed for the SEBS model, was obtained from tower metadata and was assumed constant during the simulation period. Although $h_{\mathrm{c}}$ varies over many vegetation types, accounting for its within- and inter-annual variability is usually not possible, as observed data of $h_{\mathrm{c}}$ variations are rarely recorded. Tower data were aggregated (i.e. summed for precipitation and averaged for other input variables) from their native resolution of half-hourly or hourly to 3-hourly, to match the temporal resolution of the gridded data.

\subsubsection{Description of grid-based forcing data (LandFlux version 0 forcing data set)}

Grid-based data were developed by Princeton University for the LandFlux version $0(\mathrm{~V}-0)$ data set. The variables in the $\mathrm{V}-0$ include air temperature, land surface temperature, wind speed, atmospheric pressure, specific humidity, precipitation, net radiation, NDVI and leaf area index. Net radiation data derive from the GEWEX Surface Radiation Budget (SRB) version 3 (Stackhouse et al., 2011), while land surface temperature is determined by employing a Bayesian post-processing procedure that merges High-Resolution Infrared Radiation Sounder (HIRS) retrievals with the land surface temperature data from the National Centers for Environment Prediction (NCEP) Climate Forecast System Reanalysis (CFSR) (Saha et al., 2010), as described in Coccia et al. (2015). Precipitation data are also from the NCEP CFSR product and have been bias-corrected to the Global Precipitation Climatology Project (GPCP) V2.2 data set (Adler et al., 2003). Likewise, atmospheric pressure, specific humidity and wind speed data were extracted from the CFSR reanal- ysis data. For vegetation-based parameters, NDVI data were prepared by aggregating $8 \mathrm{~km}$ resolution GIMMS NDVI data to $0.5^{\circ}$ resolution, while leaf area index data were developed by Zhu et al. (2013) through fitting GIMMS NDVI data to the Moderate Resolution Imaging Spectroradiometer (MODIS) MOD15A2 NDVI product, using a neural network technique.

The majority of variables in the global LandFlux V-0 forcing data set are at $0.5^{\circ}$ spatial and 3-hourly temporal resolution. Exceptions include the net radiation ( $1^{\circ}$ and 3-hourly), NDVI $\left(0.5^{\circ}\right.$ and bi-monthly) and leaf area index $\left(0.5^{\circ}\right.$ and monthly). For net radiation, the $1^{\circ}$ data were linearly interpolated to a $0.5^{\circ}$ resolution. The bi-monthly NDVI data were assumed constant for all 3-hourly time steps during each 15day interval, while the leaf area index data were assumed constant during each month. The canopy height over shrubland and forest biomes was assumed fixed and was estimated using a static canopy height product developed by Simard et al. (2011). For grassland and cropland biomes, where the dynamics of canopy height can be considerable, canopy height was calculated using Eq. (1), derived from Chen et al. (2012):

$$
\begin{aligned}
h_{\mathrm{c}}= & h_{\mathrm{c}}^{\min }+\frac{h_{\mathrm{c}}^{\max }-h_{\mathrm{c}}^{\min }}{\mathrm{NDVI}_{\max }-\mathrm{NDVI}_{\min }} \\
& \times\left(\mathrm{NDVI}-\mathrm{NDVI}_{\min }\right),
\end{aligned}
$$

where $h_{\mathrm{c}}^{\min }$ and $h_{\mathrm{c}}^{\max }$ are the minimum and maximum canopy height and were obtained from the static vegetation table of the North American Data Assimilation System (NLDAS) (available from http://ldas.gsfc.nasa.gov/nldas/web/web.veg. table.html). $\mathrm{NDVI}_{\min }$ and $\mathrm{NDVI}_{\max }$ are the minimum and maximum NDVI, respectively, and were calculated on a pixel-wise basis for each calendar year. The JPL static vegetation height was aggregated linearly from $1 \mathrm{~km}$ to $0.5^{\circ}$. Likewise, the NDVI derived canopy height was calculated at $8 \mathrm{~km}$ resolution and then aggregated to $0.5^{\circ}$. Similar to the tower-based data, the methodology of Jiménez-Muñoz 
et al. (2009) was used for the gridded forcing to estimate the fractional vegetation cover data from NDVI data. The ground heat flux at the grid-scale was calculated as a fraction of net radiation using fractional vegetation cover, following $\mathrm{Su}$ (2002).

\subsubsection{Model-specific forcing data and data sources}

In addition to the data described above and shown in Table 1, both GLEAM and SEBS have some model-specific forcing data requirements. For SEBS, information on land surface temperature, wind-speed and canopy height are required. At the tower scale, these data are provided by available meteorological forcing or metadata descriptions in the case of canopy height. At the grid scale they are provided by a combination of the LandFlux V-O data set and an adapted JPL static vegetation height, as described in Sect. 2.1.2. GLEAM-based simulations require information on soil properties, vegetation optical depth (VOD), satellite soil moisture, snow water equivalent, lightning frequency and vegetation cover fraction. Soil properties data for GLEAM include field capacity, critical soil moisture and wilting point soil moisture thresholds. Data for these were obtained from the Global Gridded Surfaces of Selected Soil Characteristics data set of the International Geosphere-Biosphere Programmes Data and Information System (IGBP-DIS), available from Oak Ridge National Laboratory Distributed Active Archive Center (http://www.daac.ornl.gov). Soil properties data were used in their native 5 arcmin resolution for tower-based analysis, but were aggregated to $0.5^{\circ}$ for gridbased assessment. Vegetation optical depth data were from Liu et al. (2011b) using a merged product from multiple microwave-based satellite data. The $0.25^{\circ}$ spatial and daily temporal resolutions VOD data were gap filled as described by Miralles et al. (2011a). Soil moisture data assimilated in GLEAM comes from ESA's Climate Change Initiative (CCI) WACMOS data set (Liu et al., 2012) produced from both active and passive satellite microwave data at $0.25^{\circ}$ and daily resolution. Snow water equivalent data are from the GlobSnow product version 1.0 (Luojus et al., 2010); as GlobSnow covers the Northern Hemisphere only, Global Monthly Snow Water Equivalent Climatology data from the National Snow and Ice Data Center (NSIDC) (Armstrong et al., 2005) are used for the BW-Ma1 tower (see Table A1) located in the Southern Hemisphere. Both GlobSnow data and the NSIDC product are at approximately $0.25^{\circ}$ spatial and daily temporal resolutions. Lightning frequency data are based on the Combined Global Lightning Flash Rate Density monthly climatology at $0.5^{\circ}$ (Mach et al., 2007) and it is used to calculate a climatology of rainfall rates (Miralles et al., 2010). Finally, vegetation cover fractions are derived from the MODIS MOD44B product (Hansen et al., 2005). The MODIS continuous cover factions describe every pixel as a combination of its fractions of water, tall canopy, short vegetation and bare soil. The temporal average of fractions is used here for the
MODIS period, providing only a static cover fraction for the GLEAM simulations. The MOD44B product is available at $250 \mathrm{~m}$ and $0.25^{\circ}$ resolution. For tower-based analysis, cover fractions are at $250 \mathrm{~m}$ resolution, but for grid-based analysis the $0.25^{\circ}$ MOD44B product was aggregated to $0.5^{\circ}$.

Table 1 summarises the different sources and spatiotemporal scales of the data that were used for both the towerand grid-based flux simulations. As noted earlier, the temporal analysis encompasses the period 1997-2007, although as defined in Fig. A1, the individual tower records do not necessarily provide uninterrupted observations during this time range.

\subsubsection{Definition of selected biome type and climate zones}

The specific biomes examined in this work include wetland (WET), grassland (GRA), cropland (CRO), shrubland (SHR), evergreen needleleaf forest (ENF), evergreen broadleaf forest (EBF) and deciduous broadleaf forest (DBF). Biome type was specified in FLUXNET metadata records for each of the individual tower sites and follows the International Geosphere-Biosphere Programme (IGBP) classification. For simplicity, the shrubland biome is comprised of closed shrubland, woody savannah and mixed forest biomes. The number of towers for each biome type varies, with fourteen for evergreen needleleaf forest, ten for grassland, seven for cropland, seven for deciduous broadleaf forest, four for shrubland, two for wetland and only one for evergreen broadleaf forest (see Table A1). The climate zones include boreal (BOR), sub-tropical (subTRO), temperate (TEMP), temperate-continental (TempCONT) and dry (DRY) for arid and semi arid regions. These zones were prescribed from the tower-specific metadata, which were in turn derived from Rubel and Kottek (2010), based on a KöppenGeiger climate classification. As with biome type, the towers are not evenly distributed across climate zones, with fifteen for temperate, eleven for sub-tropical, eight for temperatecontinental, five for boreal and six for dry regions (see Table A1).

\subsection{LandFlux model descriptions}

Following are brief descriptions of the models employed in this analysis. For a more comprehensive explanation of the implementation of these different schemes, the reader is referred to the principal model references as well as the recent contributions of Ershadi et al. $(2014,2015)$.

\subsubsection{SEBS}

SEBS is a widely employed process-based model used in the estimation of evaporation. The model uses a variety of land surface and atmospheric variables and parameters for simulating the transfer of heat and water vapour from the land surface to the atmosphere. To do so, the model first esti- 
mates the representative roughness of the land surface and then uses roughness parameters, temperature gradient and wind speed data to estimate sensible heat flux via a set of flux-gradient equations describing the transfer of heat from the land surface to the atmosphere. Depending on the atmospheric boundary layer height, the model uses either the Monin-Obukhov similarity theory or the bulk atmospheric similarity theory equations (Brutsaert, 2005). The model estimates the sensible heat flux of hypothetically wet and dry conditions and uses these extreme-cases to calculate the evaporative fraction. Evaporation is then calculated as a fraction of the available energy. The model requires accurate values of net radiation, land surface temperature, air temperature, humidity, wind speed and vegetation phenology to calculate surface fluxes. SEBS relaxes the need for parameterisation of the surface resistance, but is sensitive to aerodynamic resistance parameterisation (Ershadi et al., 2013). Further details on SEBS and its model formulation can be found in $\mathrm{Su}$ (2002).

\subsubsection{PT-JPL}

The PT-JPL model of evaporation uses a minimum of meteorological and remote sensing data and has been employed in a number of studies to estimate regional- and global-scale flux responses (Fisher et al., 2008; Sahoo et al., 2011; Vinukollu et al., 2011b, a; Badgley et al., 2015). A key characteristic of the model is the use of bio-physiological properties of the land surface to reduce Priestley-Taylor potential evaporation to actual values. The PT-JPL is a three-source model in which the total evaporation is partitioned into soil evaporation $\left(\lambda E_{\mathrm{s}}\right)$, canopy transpiration $\left(\lambda E_{\mathrm{t}}\right)$, and wet canopy evaporation $\left(\lambda E_{i}\right)$, i.e. $\lambda E=\lambda E_{\mathrm{s}}+\lambda E_{\mathrm{t}}+\lambda E_{i}$. The model first partitions the total net radiation to soil and vegetation components and calculates potential evaporation for soil, for canopy and for the wet canopy. The model then determines a set of constraint multipliers to represent the impacts of green canopy fraction, relative wetness of the canopy, air temperature, plant water stress and soil water stress on the evaporative process. The model uses the constraint multipliers to reduce the potential evaporation to actual values for each component of the system. PT-JPL does not calibrate or tune parameter values and does not use wind speed data or parameterisations of the aerodynamic and surface resistances. However, the model does require accurate estimates of optimum temperature $\left(T_{\text {opt }}\right)$ (Potter et al., 1993) for canopy transpiration. The optimum temperature is the air temperature at the time of peak canopy activity, when the highest values of absorbed photosynthetically active radiation and minimum values of vapour pressure deficit occur. Further details of the PT-JPL model can be found in Fisher et al. (2008).

\subsubsection{PM-Mu}

The PM-Mu was expanded from a two-source PenmanMonteith implementation (Mu et al., 2007) to a three-source version (Mu et al., 2011), which forms the basis behind the estimation of global evaporation in the MOD16 product (Mu et al., 2013) (NB the PM-Mu nomenclature used herein reflects an identical description used in Michel et al. (2015) and Miralles et al. (2015), where it is referred to as PM-MOD). Evaporation in the PM-Mu model is the sum of soil evaporation, canopy transpiration and evaporation of the intercepted water in the canopy, i.e. $\left(\lambda E=\lambda E_{\mathrm{s}}+\lambda E_{\mathrm{t}}+\lambda E_{i}\right)$. Estimation of evaporation for interception and transpiration components is based on the Penman-Monteith equation (Monteith, 1965). Actual soil evaporation is calculated using potential soil evaporation and a soil moisture constraint function from the Fisher et al. (2008) model. This function is based on the complementary hypothesis (Bouchet, 1963), which defines land-atmosphere interactions from air vapour pressure deficit and relative humidity. Evaporation components are weighted based on the fractional vegetation cover, relative surface wetness and available energy. Parameterisation of aerodynamic and surface resistances for each source is based on extending biome-specific conductance parameters from the stomata to the canopy scale, using vegetation phenology and meteorological data. In contrast to the majority of Penman-Monteith type models, the PM-Mu does not require wind speed and soil moisture data for parameterisation of resistances. However, global application of the model requires consideration of the fact that resistance parameters were calibrated against data from a set of eddycovariance towers. One issue that may influence model simulations is that this parameterisation approach was developed at the daily scale. However, both the present and also a recent related study (Miralles et al. 2015) suggest no obvious impact for sub-daily application. Further details on PM-Mu can be found in Mu et al. $(2011,2013)$.

\subsubsection{GLEAM}

GLEAM (Miralles et al., 2011a) has been used not only in estimating global evaporation (Miralles et al., 2011b) but also in detection and evaluation of heatwaves (Miralles et al., 2014a), climate variability (Miralles et al., 2014b) and land-atmospheric feedbacks (Guillod et al., 2015). Designed as a satellite data-based model, GLEAM first estimates interception loss using the analytical method of Gash (1979) and then applies the Priestley-Taylor equation to calculate potential evaporation for soil and vegetation. Like PT-JPL, the model constrains the potential evaporation values to actual values by applying a stress factor, although GLEAM is based on different assumptions and encompasses both moisture availability in a multi-layered soil system and vegetation water content inferred from vegetation optical depth data (Liu et al., 2011b). In contrast to SEBS, PT-JPL and PM- 
$\mathrm{Mu}$, the GLEAM model is equipped with routines to quantify sublimation of snow-covered regions, to estimate open-water evaporation and to assimilate remote sensing soil moisture data. Routine application of GLEAM is usually performed in time-series mode, in which the model tracks the changes of soil moisture state across time steps. Here, to allow for the application of the model at the tower-scale, gaps in the tower data were filled by establishing correlation between the variables in tower- and grid-based data. Simulated evaporation values were filtered from the analysis for these gap-filled periods. Further details on GLEAM can be found in Miralles et al. (2011a, b).

\subsection{Model simulation and analysis}

The four selected models were forced with both tower- and grid-based data. The results were then filtered for daytimeonly periods, defined as when the shortwave downward radiation exceeds $20 \mathrm{~W} \mathrm{~m}^{-2}$, to avoid issues associated with negative net radiation and night-time condensation. The data were also filtered for rain events, for negative sensible and latent heat flux observations, for low quality or gap-filled tower records, for frozen land surfaces and for times in which air temperature was less than or equal to $0^{\circ} \mathrm{C}$. The performance of the models was evaluated for individual towers, for the collection of data from all towers, for towers classified across biome types and for towers classified across climate zones.

To evaluate the skill of the models, we used traditional scatter plots and common statistical metrics including the coefficient of determination $\left(R^{2}\right)$, slope $(m)$ and $y$ intercept $(b)$ of the linear regression, the root mean square difference (RMSD), relative error $\left[\mathrm{RE}=\mathrm{RMSD} / \operatorname{mean}\left(\lambda E_{\mathrm{obs}}\right)\right]$ and the Nash-Sutcliffe efficiency (NSE) (Nash and Sutcliffe, 1970). In developing these performance metrics, simulated evaporation was compared with tower-observed evaporation $\left(\lambda E_{\text {obs }}\right)$ that were corrected for non-closure using the energy residual technique, as described in Ershadi et al. (2014). Scatter plots of matching percentiles (referred to hereafter as percentile plots) of observed evaporation vs. simulated values from the 1st to 99th percentile increment were also used (Sect. 3.1). The 25th percentile $\left(Q_{25}\right)$, median $\left(Q_{50}\right)$ and 75th percentile $\left(Q_{75}\right)$ were used for further model assessment. To establish the response of the models to water availability at individual tower sites, we calculated an aridity index as $\mathrm{AI}=$ $P / E_{\mathrm{p}}$, with $P$ the annual precipitation $\left(\mathrm{mm} \mathrm{yr}^{-1}\right)$ and $E_{\mathrm{p}}$ the annual potential evaporation $\left(\mathrm{mm} \mathrm{yr}^{-1}\right)$, calculated using a Priestley-Taylor equation and assuming an alpha-coefficient of 1.26. LandFlux V-0 data (Sect. 2.1.2) at 3-hourly resolution were used to calculate aridity index values and an average value was calculated to represent the state of water availability at specific tower locations.

\section{Results}

\subsection{Relative performance of the models when using tower-based and gridded data}

Figures 2 and 3 show scatter plots, percentile plots and relevant statistical metrics of the modelled evaporation for all of the available 3-hourly data records from across the 45 towers (representing 115153 records in total). For the tower-based analysis (see Fig. 2), PT-JPL presents the best overall performance with lower model spread and an $\mathrm{RMSD}=61 \mathrm{~W} \mathrm{~m}^{-2}$, RE $=0.41, R^{2}=0.71$ and an $\mathrm{NSE}=0.65$. The model slightly underestimates evaporation, with a slope of linear regression equal to 0.91 and with the majority of the percentile plot (up to $Q_{75}$ ) located just under the $1: 1$ line. When considering results across all towers, GLEAM presents comparable statistical performance to PT-JPL, with an RMSD $=64 \mathrm{~W} \cdot \mathrm{m}^{-2}$, $\mathrm{RE}=0.43$ and an NSE $=0.62$. GLEAM tends to slightly underestimate evaporation, with the slope of linear regression equal to 0.84 and with the percentile plot being located under the $1: 1$ line. SEBS generally overestimates evaporation and has the lowest overall performance, with an $\mathrm{RMSD}=101 \mathrm{~W} \mathrm{~m}^{-2}, \mathrm{RE}=0.68$ and $\mathrm{NSE}=0.24$, even though it has one of the highest $R^{2}$ values at 0.72 . For PM$\mathrm{Mu}$, the model tends to underestimates evaporation, resulting in an $\mathrm{RMSD}=78 \mathrm{~W} \mathrm{~m}^{-2}, \mathrm{RE}=0.52$ and an $\mathrm{NSE}=0.45$. Overall, the PT-JPL and GLEAM seem to present as more robust candidate models for estimation of evaporation, at least in terms of their statistical response at the tower scale. All models show a large spread around the fitted linear regression line. While the summary statistics are useful metrics of performance, the inter-tower variability of the models is an important element of this work and will be discussed further in the following sections.

The effect of using globally gridded forcing data on the evaporation models is presented in Fig. 3. Apart from providing a direct evaluation on the accuracy of the global LandFlux product, assessing flux response to a change in forcing aids in diagnosing the model sensitivity to data uncertainties (which are inherent in any data product). Likewise, an indirect assessment of the issue of footprint mismatch between the gridded data $\left(0.5^{\circ}\right)$ and the eddy-covariance tower (hundreds of metres) can also be inferred. Figure 3 clearly shows that use of the grid-based data reduces the performance of all models relative to the tower-based runs, with all statistics degrading with a change in forcing resolution. SEBS displayed the largest sensitivity to forcing data, with a 0.4 decrease in NSE and a $28 \mathrm{~W} \mathrm{~m}^{-2}$ increase in RMSD. The sensitivity of PT-JPL and GLEAM to the use of gridded data was lower, with both showing an approximately 0.3 decrease in NSE and around $22 \mathrm{~W} \mathrm{~m}^{-2}$ increase in RMSD when assessing the grid-based analysis. Overall, PM-Mu shows the lowest sensitivity to forcing, with a 0.26 decrease in NSE and $18 \mathrm{~W} \mathrm{~m}^{-2}$ 

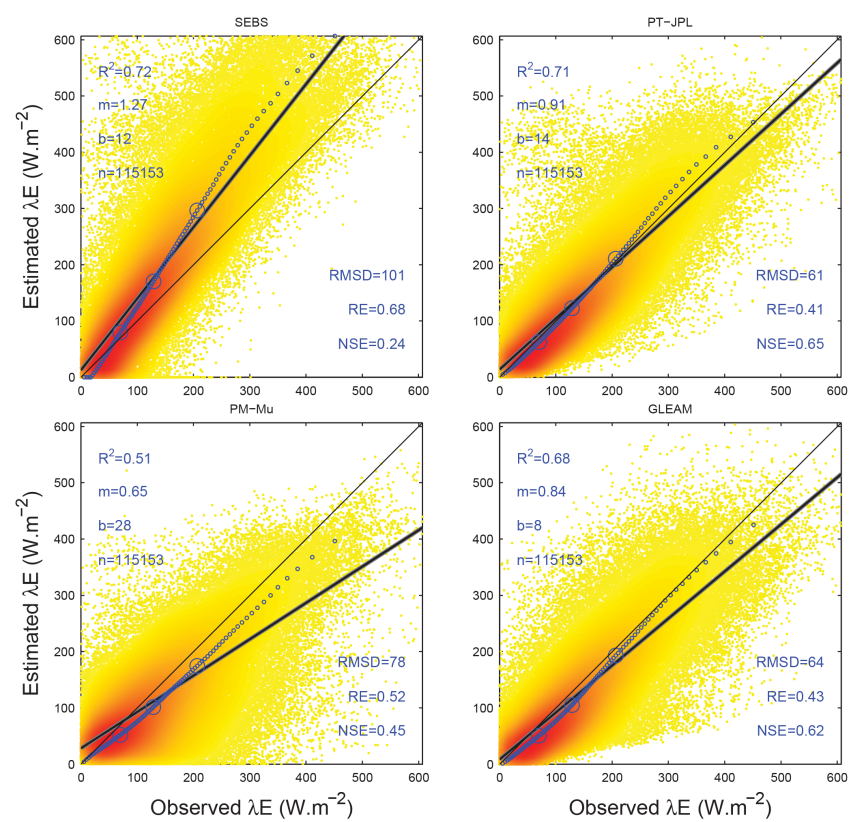

Figure 2. Scatter plots of observed vs. simulated latent heat flux for tower-based data. Colors show the frequency of values from high (red) to low (yellow). The thick black line represents the linear regression, while the thin line is the $1: 1$ line. The series of small circles show the percentile increments of data from the 1st to 99th, with large circles denoting the 25 th, 50 th and 75 th percentiles. The statistics shown on each figure provide coefficient of determination $\left(R^{2}\right)$, slope $(m), y$ intercept $(b)$, number of data records $(n)$, the root-mean-squared difference (RMSD), relative error (RE) and the Nash-Sutcliffe efficiency (NSE).

increase in RMSD, albeit presenting the lowest correlation and slope of linear regression for all model responses.

Overall, these results confirm that all models display a relatively high sensitivity to changes in the type and quality of input forcing data. While gridded forcing data are expected to have a mismatch with the tower-based forcing due to their larger pixel (and footprint) sizes, this spatial mismatch will impact all of the applied models, albeit to a lesser or greater extent, depending on forcing data requirements. Although spatial scale no doubt plays a major role in decreasing model efficiencies at grid scales, a key reason for the differences in tower- vs. grid-based results relates to internal inconsistencies within the gridded forcing data. For instance, SEBS is known to be particularly sensitive to the temperature gradient between the land surface and the atmosphere (van der Kwast et al., 2009; Ershadi et al., 2013). While the temperature gradient at the tower scale is more reliable due to application of the tower-based sensors for air temperature and land surface temperature, obtaining such consistency is harder when different sources of forcing data are employed (see Sect. 2.1). Not surprisingly, results also indicate that those models that use fewer inputs show lower sensitivity to changes in the forcing. As such, any inconsistency between the tower and
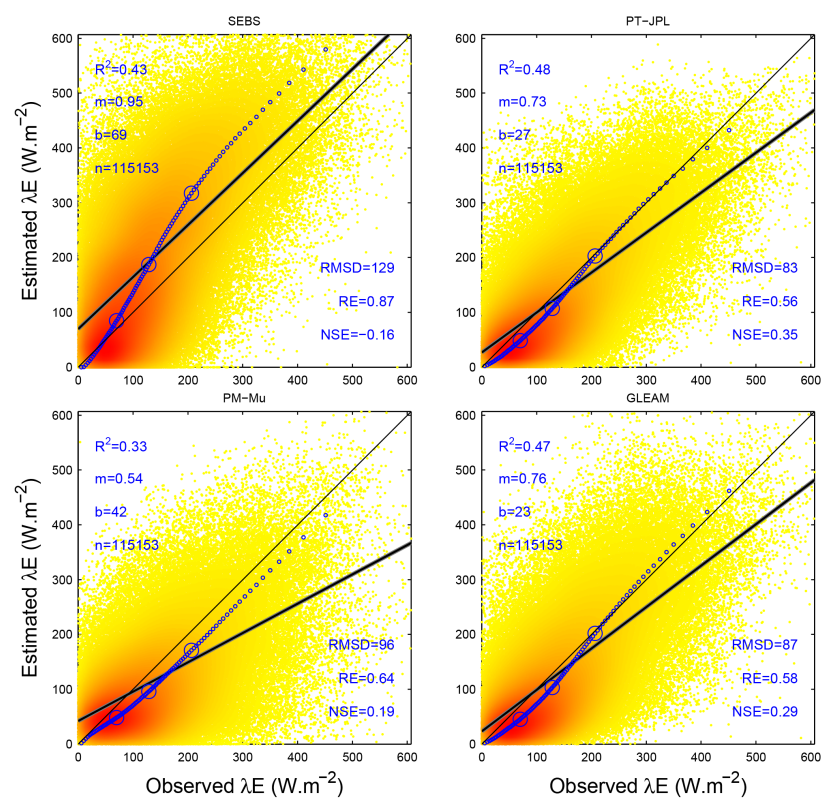

Figure 3. Scatter plots of observed vs. simulated evaporation for grid-based data. Colors show the frequency of values from high (red) to low (yellow). The thick black line is the linear regression and the thin line is the $1: 1$ line. The series of small circles show the percentile increments of data from the 1st to 99th, with large circles denoting the 25 th, 50 th and 75 th percentiles. The statistics shown on the graphs are coefficient of determination $\left(R^{2}\right)$, slope $(m), y$ intercept $(b)$, number of data records $(n)$, the root mean squared difference (RMSD), relative error (RE) and the Nash-Sutcliffe efficiency (NSE).

gridded data is likely to have less influence on the PT-JPL, GLEAM and PM-Mu models than it will on SEBS, which in addition to vegetation height, requires both land surface temperature and wind speed data: two variables with considerable spatial variability. Disentangling the varying influence of model structural and forcing data uncertainty requires focused attention and is examined further in the Discussion section.

The large spread of data in the scatter plots indicates that there is considerable variability in the performance of the models at individual towers, irrespective of whether tower or gridded data are used. Of course, it may also be indicative of systematic biases in the in situ data, which vary from one tower to another and subsequently impact on model spread; however, this is non-trivial to determine. To investigate the nature of this variability, we extend the analysis by developing time series of $R^{2}, \mathrm{RE}$ and NSE at 3-hourly resolution for individual tower locations, as shown in Fig. 4. To examine performance as a function of hydrological condition, the towers are arranged by degree of increasing aridity, as determined by calculation of an aridity index (see Sect. 2.3), with left-to-right representing the transition from wet-to-dry and 

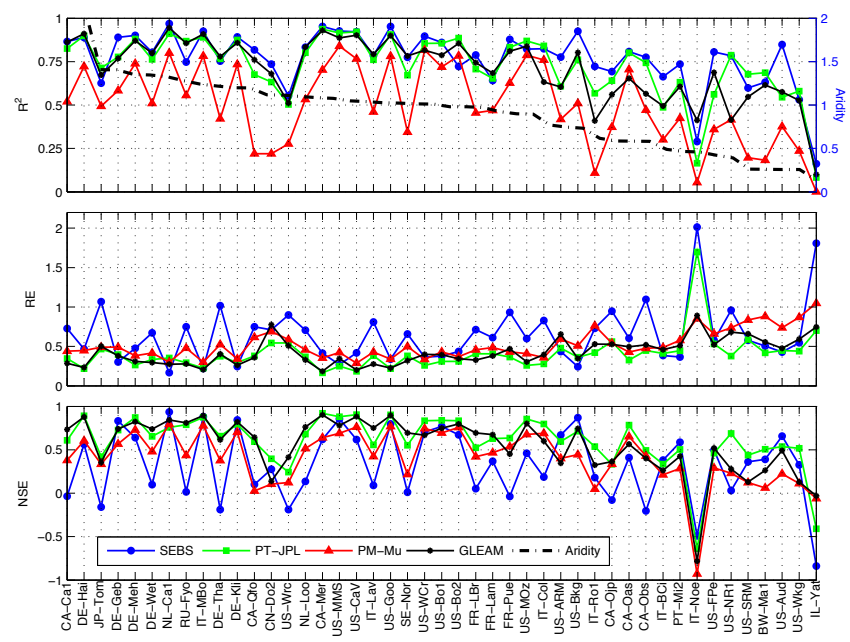

Figure 4. Comparison of the performance skill of the models in reproducing evaporation for the tower-based analyses. $R^{2}$ is the coefficient of determination, $\mathrm{RE}$ is relative error (lower is better) and NSE is the Nash-Sutcliffe efficiency (higher is better). Towers are arranged from left to right based on an aridity index (secondary $y$ axis).

describing an aridity index varying between approximately 2 and 0 .

From Fig. 4 it can be observed that there is a general downward trend in both $R^{2}$ and NSE as aridity increases, with a slight upward trend reflected in RE. In terms of $R^{2}$, most of the models (except for PM-Mu) show some consistency in performance until an aridity index of around 0.7 , wherein models start to diverge. Similar agreement is seen in the relative error plot, although the outlier here is SEBS, which shows variable performance unrelated to aridity changes. Examining the Nash-Sutcliffe efficiency allows for a clearer evaluation of model response to be obtained. For this metric, PT-JPL and GLEAM display relatively good correspondence for most of the towers, but start to diverge more regularly for aridity indices below 0.8 . Overall, PT-JPL presents a marginally better response than GLEAM, with higher values of NSE and $R^{2}$ and lowest values of RE produced across the majority of towers. Similar results are expressed in Fig. A2, which presents the same tower-based inter-comparison as in Fig. 4, but for the grid-scale model simulations.

From Fig. 2 it was observed that SEBS presented the lowest values of NSE and highest values of RE, while PM-Mu had the lowest values of $R^{2}$. Highlighting the importance of examining a range of statistical metrics, the $R^{2}$ values for SEBS are actually comparable to those of PT-JPL and GLEAM, or even higher for a majority of towers that have an aridity index less than 0.7 . Inspection of individual towerbased scatter plots for each of the models (not shown) illustrated that while the SEBS evaporation has a strong linear relationship with observed values for a majority of towers, the linear regression line exhibits a large slope, indicating an overestimation in SEBS predictions. Those towers that exhibit drops in NSE (and rise in RE) for the SEBS model (e.g. DE-Tha, NL-Loo, US-Wrc, FR-Pue; see Table A1) are located mainly in shrubland and forest biomes, suggesting a dependency of SEBS model performance that is tied to land surface vegetation characteristics. Although statistical variations are evident in all models, the greater response variability in SEBS is likely due to problems in simulating heat transfer within the roughness sub-layer (RSL), which often forms over tall and heterogeneous land surfaces (Harman, 2012). We explore the issue of skill dependency of certain models to biome type and climate zone in Sect. 3.2 and 3.3.

As noted, Fig. 4 shows a general decrease in the predictive skill in all models where towers have an aridity index less than 0.7 , but particularly so for PM-Mu and SEBS. These reductions may in part be due to data uncertainties in tower observations that originate from the advection of dry air into the tower footprint, or to a reduced capacity of the models to reproduce the evaporative response when evaporation represents a small fraction of the total available energy. Two towers at which all models display poor performance are IT-Noe and IL-Yat (see Fig. 1). It seems likely that IT-Noe is influenced by strong advection of moist air from the Mediterranean Sea, while IL-Yat is influenced by advection of hot and dry air from surrounding desert regions. None of the models in this study are able to specifically account for advection and are thus prone to misrepresenting the observed evaporative response.

\subsection{Performance of the models across biomes}

The variability in model performance across the tower sites observed in Figs. 4 and A2, indicates that a biome-specific assessment could be useful to determine whether the performance of the models is also correlated to the underlying land cover, in addition to any aridity influence. Figure 5 presents the $R^{2}, \mathrm{RE}$ and NSE for each of the models for the seven different biome classes. The analysis was conducted using the higher quality tower-based simulations for all available 3-hourly data. One immediate highlight from Fig. 5 is the relatively poor performance of all models over shrubland sites, where low values of NSE (i.e. NSE $\leq 0.05$ ) and reduced $R^{2}$ can be observed. Ershadi et al. (2014) observed a similarly poor response over shrublands in a separate towerbased analysis that employed some of the same models examined here. They attributed the result to difficulties in the parameterisation of the models over such landscapes due to the strong heterogeneities present in these environments, as well as inherent water limitations. For instance, the capacity of the GIMMS NDVI data with $8 \mathrm{~km}$ spatial resolution is clearly insufficient in effectively parameterising the roughness for SEBS, resistances for PM-Mu and constraint functions for the PT-JPL.

Excluding shrublands from the analysis, the PT-JPL is one of the best performing models across the remaining biomes, 

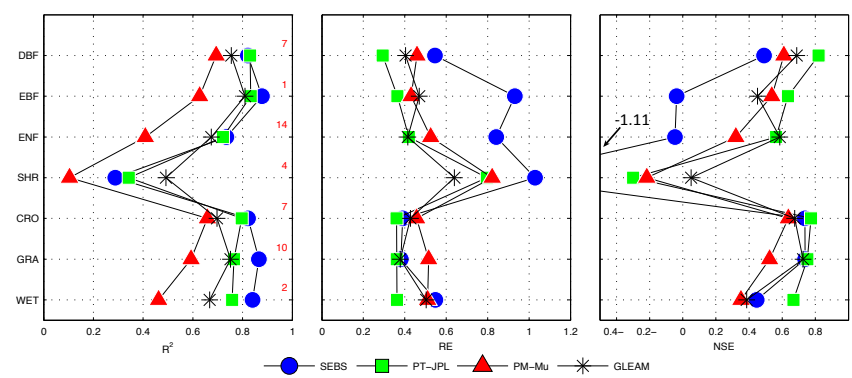

Figure 5. Coefficient of determination $\left(R^{2}\right)$, relative error (RE) and Nash-Sutcliffe efficiency (NSE) for models across different biome types. Each point represents the collection of all available 3-hourly records of towers located within the selected biome, with the number of towers shown on the secondary $y$ axis of the $R^{2}$ plot in red. NSE for the shrubland response of SEBS is printed.

having the highest values of NSE and $R^{2}$ and lowest relative errors. Consistency in the performance of PT-JPL across biome types has been reported in earlier studies (Vinukollu et al., 2011a; Ershadi et al., 2014) and was variously ascribed to the formulation of its constraint functions (see Sect. 2.2.2) and the minimal forcing data requirements, which reduce its sensitivity to uncertainties in input data. GLEAM closely follows PT-JPL for evergreen needleleaf forest and grassland biomes, but shows marginally lower NSE values for other biomes. Figure 5 also indicates that while SEBS has relatively high values of $R^{2}$ over the majority of biome types, it fails to provide sufficient predictive skill for the estimation of evaporation over shrublands and forest biomes. These biome types are characterised by tall and heterogeneous canopies, within which the roughness sub-layer forms. The reduced capacity of the SEBS flux gradient functions in simulating heat transfer within the roughness sub-layer has been highlighted previously (Weligepolage et al., 2012; Ershadi et al., 2014). Although performing poorly in shrubland and forest biomes, the SEBS model exhibits a comparatively good performance across wetlands, grasslands and croplands, where shorter canopies dominate. PM-Mu presents the lowest values of $R^{2}$ across all biomes, although the model presents reasonable NSE values over cropland (0.64) and broadleaf forest (>0.54) biomes. Improved performance of the PM-Mu model over croplands has been observed in a recent study (Ershadi et al., 2015), but the key reasons for low $R^{2}$ values of the model across other biomes is not immediately apparent and requires further investigation.

Percentile plots of the 3-hourly tower-based results were used to identify whether a model under- or over-estimates evaporation across its distribution function. From Fig. 6 it can be seen that SEBS clearly overestimates while PM-Mu underestimates evaporation across all biome types, reflecting those results presented in Fig. 2. The percentile plots for SEBS are close to the 1:1 line for grassland and cropland biomes that have short canopy height, confirming the obser-
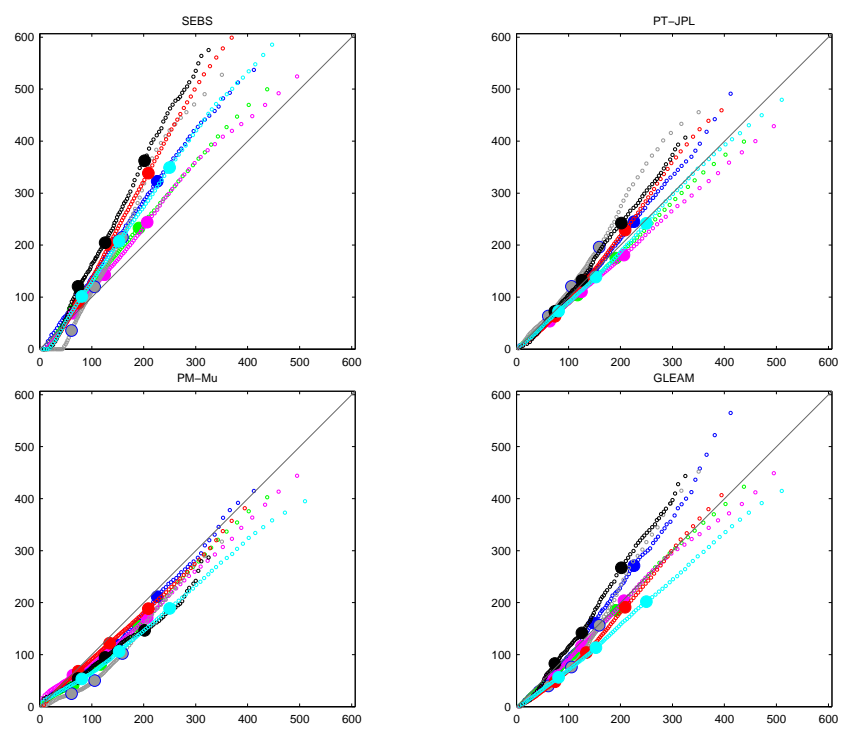

- wet - gra - cro

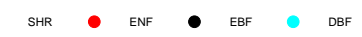

Figure 6. Percentile plots of observed ( $x$ axis) vs. estimated latent heat flux ( $y$ axis) at 3-hourly resolution for the tower-based analysis across the seven studied biomes. Percentiles encompass the 1 st to 99th range in 1 percent increments, with $Q_{25}, Q_{50}$ and $Q_{75}$ denoted by large coloured circles.

vations made for Figs. 4 and 5. PT-JPL shows good model reproduction of observed values over grassland and deciduous broadleaf forest biomes, with the percentile plots close to the $1: 1$ line. However, the model slightly underestimated evaporation for croplands and overestimated evaporation for wetlands, with the tails (percentiles greater than $Q_{75}$ ) reflecting greater divergence than the bulk of the distribution. The rate of overestimation was higher for evergreen needleleaf forest, evergreen broadleaf forest and for shrubland biomes. Figure 6 also shows that GLEAM presents strong performance over grasslands, croplands and evergreen needleleaf forest sites, underestimated evaporation across deciduous broadleaf forest sites and tended to overestimate evaporation across the remaining biomes (wetlands, shrublands and evergreen broadleaf forests).

Overall, all models show a tendency towards reduced performance when applied over forest biomes, but improved performance over shorter canopies. These results may be reflecting the fundamental physical basis behind approaches such as the base Penman-Monteith (Penman, 1948), Priestley-Taylor (Priestley and Taylor, 1972) and Monin-Obukhov flux gradient functions, which were developed for such surface types (Brutsaert, 1982), highlighting the challenges inherent in global-scale application of such models, especially over diverse land cover types.

To further evaluate the influence of biome type on evaporation estimation and to discriminate the role of individual forcing variables in impacting model efficiencies, the NSE and $R^{2}$ values between tower- and grid-based data were cal- 
culated for the flux response, as well as for key forcing variables such as net radiation, land surface temperature, air temperature, wind speed, specific humidity, fractional vegetation cover and leaf area index. As can be seen in Fig. 7, agreement between tower-based and grid-based net radiation data is relatively high across all biomes, but especially so over forest biomes (NSE $\geq 0.67$ ). Grid-based wind speed data have the most variable agreement with tower data, with $R^{2}$ and NSE values generally lower than other selected variables across all of the examined biomes. Air temperature shows good agreement, with both high NSE values (NSE $\geq 0.7$ ) and high $R^{2}$ values $\left(R^{2} \geq 0.84\right)$. Specific humidity data are also well reproduced (NSE $\geq 0.72$ ), as is land surface temperature with an NSE $\geq 0.80$ for all biomes. In sharing a common GIMMSNDVI-based derivation, the agreement for fractional vegetation cover and leaf area index data is reasonable over the majority of biomes, except over evergreen broadleaf forest, where both the $R^{2}$ and NSE are low.

The lower panel of Fig. 7 show $R^{2}$ and NSE values for both the tower- and grid-based simulations against eddycovariance observations for each of the models, discriminated by biome type. As can be seen, the performance of all models is reduced across all biomes when grid-based forcing data is used, a result reflected in all cases by relatively lower NSE and $R^{2}$ values. PM-Mu had the smallest and SEBS had the largest decrease in performance over a majority of the biomes, in accordance with the findings of Sect. 3.1. PT-JPL and PM-Mu had a relatively constant decrease in NSE and $R^{2}$ for the grid-based simulations. Decreased modelling performance was also maintained for GLEAM, except over the single evergreen broadleaf forest tower, where a more significant departure (relative to the other biome types), was observed. SEBS showed a much larger variability in performance reduction, with smaller variations due to forcing over forest biomes and larger reductions over biomes with shorter canopies. The significant decrease in NSE for SEBS over grassland, cropland and to some extent the wetland biome, cannot be immediately associated with NSE or $R^{2}$ changes in any of the forcing variables. It is interesting that the agreement over grassland and cropland biomes between towerand grid-based variables is amongst the highest (especially for wind speed, fractional vegetation cover and for leaf area index data), yet the subsequent model performance is among the worst. The use of global statistics to evaluate model response makes discriminating the cause of this variability difficult. It is possible that the statistics are biased low due to the influence of one or a few individual towers, by errors in the forcing fields driving model parameterisations (i.e. vegetation height) or in response to model sensitivities to particular forcing variables. Either way, these results highlight the difficulties in diagnosing the cause of performance response and related sensitivity to forcing data variables in complex process-based models, which often display a high degree of interactions between the variables. Indeed, diagnosing the forcing variables responsible for reducing the efficiency of
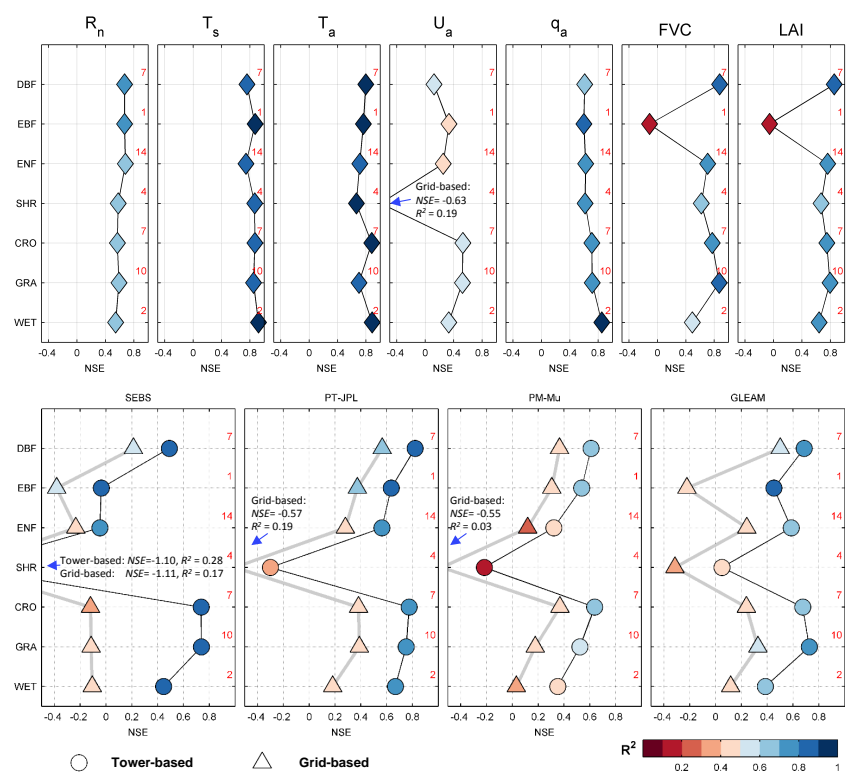

Figure 7. The upper panel presents Nash-Sutcliffe efficiency (NSE; $x$ axis) and $R^{2}$ (colour tone) between tower- and grid-based values for net radiation, land surface temperature, air temperature, wind speed, specific humidity, fractional vegetation cover and leaf area index, across the seven studied biome types. The lower panel presents the NSE ( $x$ axis) and $R^{2}$ of model simulated evaporation against closure-corrected observed values. The number of towers for each biome type used in the analysis are shown in red font on the secondary (right) axis in each of the plots. Statistics for those results beyond the range of the $x$ axis are printed separately on the plot.

particular models is not feasible with a simple correlation analysis of the input data fields, but requires a separate and focused sensitivity analysis.

\subsection{Performance of the models over climate zones}

Similar to the biome-wise analyses, an evaluation of the models was conducted across a number of distinct climate zones, with $R^{2}$, RE and NSE values for tower-based 3-hourly evaporation estimations shown in Fig. 8. Yet again, the results highlight the importance of considering a range of evaluation metrics, as the models display some variability relative to the statistical measure being employed. Overall, both PTJPL and GLEAM maintain a consistently good performance over the majority of climate zones, with PT-JPL expressing a slightly improved response over all zones except temperate, where GLEAM shows an improved simulation. In terms of $R^{2}$, PM-Mu presents the lowest values overall, while SEBS exhibits high values over the majority of climate zones, similar to the biome-based analysis. However, SEBS generally fails to reproduce the observed evaporation response, with high RE and low NSE. All models have their best performance over the temperate-continental climate zone, with high NSE and $R^{2}$ and low RE, which was followed closely by 


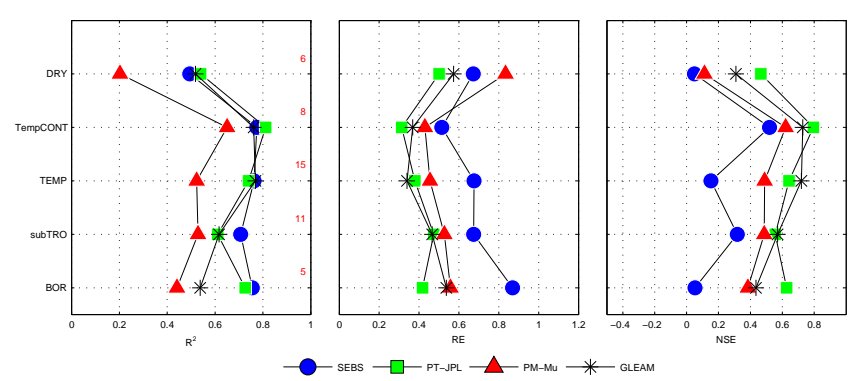

Figure 8. Coefficient of determination $\left(R^{2}\right)$, relative error (RE) and Nash-Sutcliffe efficiency (NSE) for model simulated results across the five different climate zones ( $y$ axis). The zones are represented by dryland (DRY), temperate continental (TempCONT), temperate (TEMP), sub-tropical (subTRO) and boreal (BOR). Each point represents the collection of all towers located within the selected climate zone, with the number of towers shown on the secondary $y$ axis of the $R^{2}$ panel in red.

the temperate climate zone. The lowest overall performance for all models corresponded to the dry climate zone, again reflecting the aridity-based results in Fig. 4. As discussed in Sect. 3.1, data uncertainties due to the role of advection in dry regions and difficulties in the accurate estimation when confronted with low evaporative fractions are likely reasons behind such performance reductions in dry regions.

Figure 9 displays the corresponding percentile plots of model performance over the five different climate zones. As can be seen, PT-JPL and GLEAM provide generally good performance over all climate zones, although GLEAM slightly underestimates evaporation for temperatecontinental and boreal climate zones. SEBS overestimates relative to tower-based evaporation across all biomes, while PM-Mu generally underestimates, except over temperate and temperate-continental climate zones, for which the percentile plot of PM-Mu are relatively close to the $1: 1$ line.

Similar to Fig. 7, Fig. 10 outlines the model response differentiated for the different climate zones when using gridbased forcing data. As can be seen from the lower panel, the simulation performance is reduced across all climate zones, relative to the tower data. In particular, SEBS is significantly impacted across the majority of climate zones, with both a reduction in NSE and $R^{2}$, except over boreal forests. One possible reason for this smaller variation over boreal forests could be due to lower surface-to-air temperature gradients over forests, which contributes to smaller sensible heat fluxes and consequently larger evaporative fraction values (in contrast to model performance over dry climates, where the temperature gradient is large). Nevertheless, the relationship between uncertainty in individual variables and the reduction of modelling performances is not able to be determined here. Further analysis examining the sensitivity of individual models to their forcing is required.
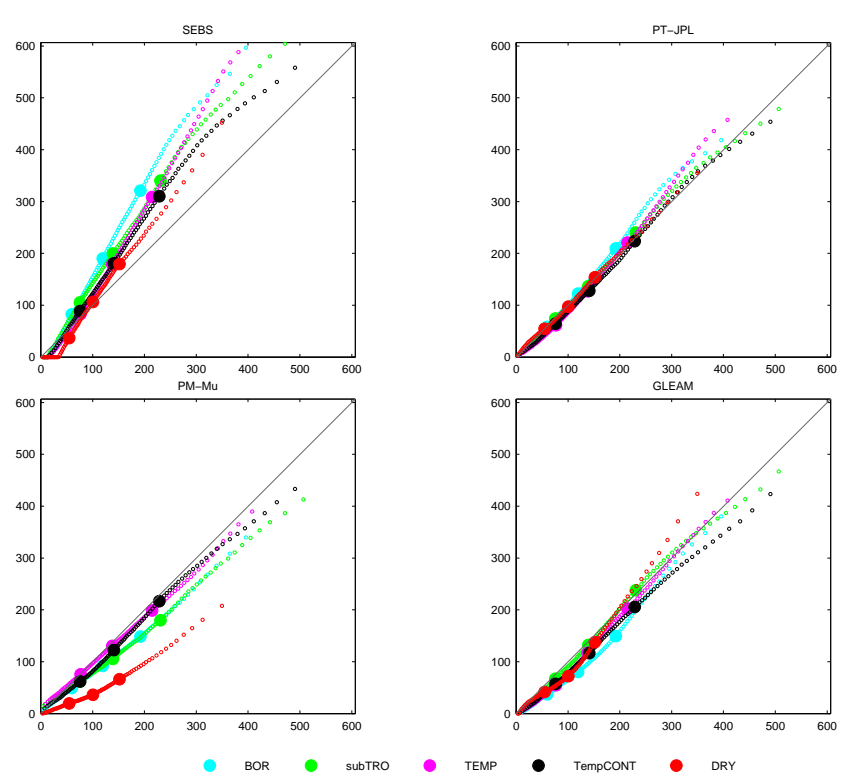

Figure 9. Percentile plots of observed ( $x$ axis) vs. estimated latent heat flux ( $y$ axis) at 3-hourly resolution for tower-based analysis and across the different climate zones. Percentiles encompass the 1 st to 99th range in 1 percent increments. $Q_{25}, Q_{50}$ and $Q_{75}$ are denoted by large circles.
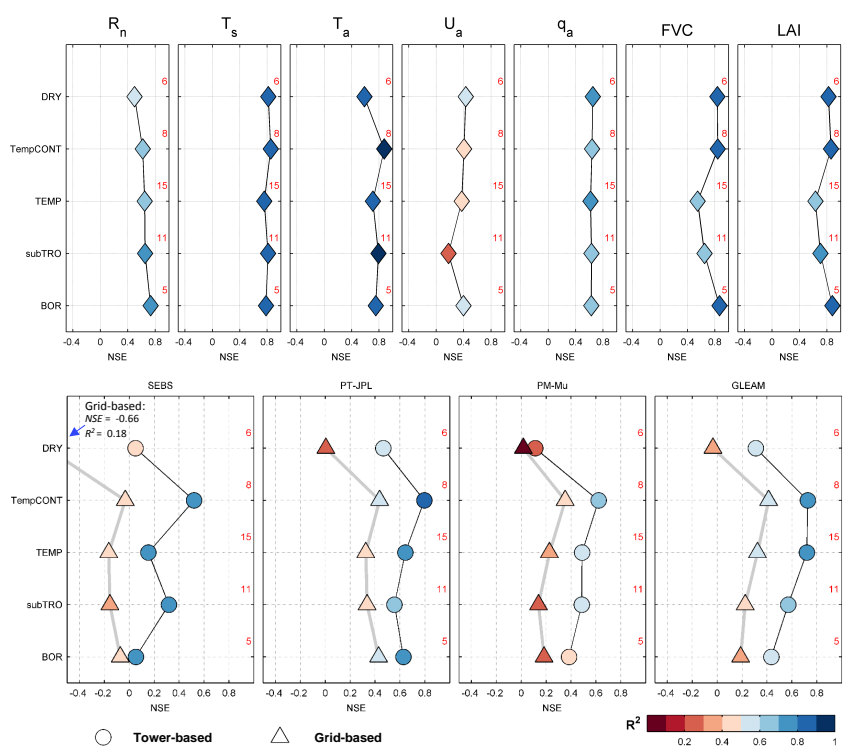

Figure 10. The upper panel shows Nash-Sutcliffe efficiency (NSE; $x$ axis) and $R^{2}$ (colour tone) between tower-based and grid-based values for net radiation, land surface temperature, air temperature, wind speed, specific humidity, fractional vegetation cover and leaf area index across the five different climate zones. The lower panel shows NSE ( $x$ axis) and $R^{2}$ of model simulated evaporation against closure-corrected observed values across climate zones. The number of towers for each biome are shown in red font on the secondary (right) axis of the plots. Statistics for the grid-based SEBS result over dry climate zone are printed. 


\section{Discussion}

Understanding the role of model forcing in influencing simulation results, as well as examining the impacts of biome type and climate zone on flux response, are important elements in the development of robust globally distributed evaporation products. The focus of this study was on evaluating a set of process-based models, to support the development of globally distributed and long-term observations of surface fluxes as part of the GEWEX LandFlux project. Overall, the PTJPL and GLEAM models provided the most consistent performance, while PM-Mu tended to underestimate and SEBS overestimate evaporation relative to the 45 eddy-covariance tower observations examined here. However, while statistical analysis allows for a pseudo-ranking of model performance, more detailed evaluation across towers, and biome and climate types highlighted the considerable within-model variability in performance. Results also demonstrated that changing the scale of input forcing data from tower- to grid-based reduced the quality of model estimates in all cases, but especially for SEBS, where a sensitivity to surface-air temperature gradients plays a strong role. In the following, we examine these results and interpret any implications for large-scale global applications.

With its relatively simple modelling structure, PT-JPL performed consistently well relative to the other models that have more complex structures and parameterisation configurations. One possible reason for this response may relate to the constraint functions of PT-JPL serving a wide range of hydro-meteorological conditions, encompassing energylimited (e.g. boreal climate) to water-limited (e.g. dry climate) conditions. The good performance of PT-JPL was also observed in a recent multi-model evaluation study, with a summary of the strengths and limitations of the model presented in Ershadi et al. (2014). GLEAM also performed well, both at the tower and at the grid-scale (see Figs. 4 and A2). Previous studies have shown that the model is sensitive to the accuracy of precipitation data (Miralles et al., 2011b), as this determines the partitioning of intercepted evaporation in the model and the root-zone soil moisture. Unfortunately, testing for such sensitivities was not possible here, as both tower- and grid-based records were filtered for rainfall events in post-processing steps, in response to the limitation of eddy-covariance observations during such events.

In terms of the NSE, $R^{2}$ and RE, PM-Mu followed PTJPL and GLEAM, with the model tending to underestimate evaporation when applied to most of the tower- and gridbased records. While reasons for this underestimation are not immediately clear, a recent study examining the structure and parameterisation of Penman-Monteith type models (Ershadi et al., 2015) showed that the PM-Mu, which has a three-source structure, under-performed relative to a singlesource (Monteith, 1965) and a two-layer approach (Shuttleworth and Wallace, 1985) across all studied biome types except croplands. An interesting aspect of Ershadi et al. (2015) was that application of the canopy transpiration resistance scheme of the PM-Mu in those simpler models improved their prediction skills. As such, the reduced performance of the PM-Mu predictions might relate to underlying structural and parameterisation issues in the model. As the operational model behind the generation of the current MOD16 global evaporation product (Mu et al., 2013), further studies to diagnose the cause of these responses are required.

Regarding assessment against the tower-based eddycovariance observations, SEBS performed relatively poorly in most statistical metrics when compared to the other models, as it overestimated evaporation across a majority of studied biomes and climate zones, except over grasslands and cropland sites with short canopies (e.g. less than $3 \mathrm{~m}$ ). Interestingly, even though generally over-predicting results, it had one of the highest $R^{2}$ values, indicating good correlation with the eddy-covariance observations. Findings from Ershadi et al. (2014) confirm the good performance of the model over short canopies and its lack of performance over shrublands and forests. In terms of performance against underlying biome type, it was observed that any performance reduction was observed mainly across shrublands and forest biomes, where the roughness sub-layer forms above the canopy (Harman, 2012). Importantly, the flux-gradient functions of the SEBS model are not parameterised to effectively simulate the heat transfer process in the roughness sub-layer, and hence the model fails to perform well (Weligepolage et al., 2012). The reliance of SEBS on an accurate representation of the surface-air temperature gradient also limits the effectiveness of the model for global application, demanding improvements in characterizing the spatial and temporal representativeness of such variables.

It is apparent from Sect. 3.2 and 3.3 that the application of gridded data for modelling evaporation inevitably reduces the predictive performance of all models, regardless of their complexity in the evaporation process or their economy in forcing data requirements. In fact, the footprint mismatch between the tower- and grid-based simulations is likely to increase uncertainties in the forcing data and cause discrepancies between the simulated and tower-based evaporation values. Importantly, comparing the models for their relative performance (see Figs. 7 and 10) reveals that the performance decrease for grid-based analysis was not equal amongst all of the models. For instance, SEBS was observed to be more sensitive to the use of gridded forcing data, most likely as a result of inconsistencies in temperature gradient fields: an aspect that has been noted previously (van der Kwast et al., 2009; Ershadi et al., 2013). Although input uncertainty also impacts the performance of PT-JPL, PM-Mu and GLEAM, the NSE and $R^{2}$ of gridded simulations for those models are closer to their tower-based counterparts. Apart from indicating a robust model structure, the reduced impact seen in these schemes may also be a consequence of avoiding the use of forcing data such as land surface temperature and wind speed data, which are known to be uncertain at both the grid and 
tower scale. Regardless of the culprit behind the observed performance discrepancy between tower and grid-based simulations, it is clear that some models are better suited to global application than others - at least given the quality of currently available global forcing data sets.

Importantly, the results presented in Sect. 3.2 and 3.3 showed that evaluating tower or grid-based statistical responses alone is not enough to identify those forcing variables most impacting model performance. Diagnosing forcing sensitivity is not trivial given non-linearities in the models and the high level of interaction within model variables and parameters. Indeed, caution is warranted in any approaches seeking to evaluate evaporation models using gridded data in isolation, as this is likely to yield unreliable performance metrics of the models. It is important to perform a parallel tower-based data assessment to increase confidence in any single models performance (Su et al., 2005) in any evaluation approach, particularly those occurring at global scales.

Although the largest possible set of eddy-covariance towers and a common set of forcing data was used to evaluate the different model simulations, there are still inevitable limitations in the evaluations. Identifying such limitations is important not only for the current evaluations but also in guiding future contributions. One such example relates to the period of tower data used for evaluation in this study (see Fig. A1), as the data record length varies amongst the towers and the data are not uniformly distributed across seasons. Moreover, the towers are not evenly distributed across the studied biomes and climate zones (see Fig. 1, Table A1), with only one tower covering the entire evergreen broadleaf forest biome and two towers covering the wetland biome. Further, no towers were available for use in arctic and tropical climate zones. Although the tropical climate zone, especially Amazonian forests, is accounted as a critical component in studies of the global water and energy cycles (Chahine, 1992; Wohl et al., 2012), relatively few towers in this zone provide land surface temperature and longwave upward radiation data needed for the SEBS model. An additional limitation is the coarse $(8 \mathrm{~km})$ spatial resolution of the GIMMS NDVI data used in the models for the tower-based analysis, as this resolution certainly does not correspond with the footprint of eddy-covariance sensors at any of the towers. Developments towards improving the availability and access to long-term high-resolution Landsat images (e.g. via Google Earth Engine; https://earthengine.google.org) might be one way to improve model forcing and evaluation exercises, especially with the development of high-resolution vegetation products (Houborg et al. 2016).

While the accuracy of individual variables in the LandFlux data set were enhanced by bias correction against independent data sources (see Sect. 2.1), diagnosing the internal consistency of the data fields (McCabe et al., 2008), especially for air temperature, land surface temperature, wind speed and humidity, is a concept that has not received much attention to date and demands more considered investigations and analysis. Internal consistency is an extremely challenging objective, but is critically important for flux estimation, where so many different forcing data are required. Essentially it demands that all required model data are derived from a common set of forcing variables, rather than by the standard approach of compilation based on availability and accessibility. The most illustrative example would be in the development of radiation data, derived here from NASA-GEWEX SRB sources (Stackhouse et al., 2011). Calculation of radiation components requires air temperature, surface temperature, land surface and vegetation features, as well as numerous other elements. However, these underlying variables are rarely if ever retained to provide a consistent overall forcing data set (i.e. the meteorological variables used in producing the SRB data are not subsequently used to drive the models). Interdependencies in forcing affect many variables in the estimation of evaporation, yet products are not developed with this simple consistency principle in mind. Apart from introducing further biases and uncertainties into model simulations, until such consistency is attained, discriminating between the impact of forcing vs. the model sensitivity to that forcing will remain extremely challenging.

From one perspective, the performance of the evaporation models examined here seems relatively poor, even when they are forced with high-quality tower-based data. PT-JPL, which was identified as one of the most consistent and best performing models, still presented a relative error of $41 \%$, with errors for GLEAM, PM-Mu and SEBS of 43, 52 and $72 \%$, respectively. However, it is important to recognise that tower-based evaluation represents one of the strictest measure of model performance and comes with its own caveats. One question that remains unanswered is whether it is even appropriate to expect models run with large-scale gridded forcing to replicate the small-scale response observed by eddy-covariance towers. The alternative perspective, given inherent uncertainties in forcing, observations and specification of model parameters, is that these results are encouraging. Broader-scale metrics such as hydrological consistency (McCabe et al., 2008), catchment-based assessments or water budget closure approaches would provide a better guide (Sheffield et al., 2009) and indeed, such evaluations will need to be performed. These questions highlight the difficulties in not just producing global estimates, but perhaps more importantly, in evaluating their quality.

The observed variability of modelling performance across the studied biomes and climate zones implies that caution is required in advocating any single model for large-scale or global application. These results are consistent with previous findings undertaken across a smaller number of towers and biome and climate types, that any one modelling approach is incapable of accurately reflecting the range of flux responses occurring across diverse landscapes (Ershadi et al., 2014, 2015). One possible solution to address this inherent model limitation is to assemble a mosaicked product based on the 
predictive skill of the model(s) over particular biomes or climate zones. Another approach might be to develop an ensemble product using a suitable multi-model blending technique, such as a Bayesian Model Averaging approach (Hoeting et al., 1999; Yao et al., 2014). Either way, it is clear that further multi-model assessments are required for progressing global-scale flux characterisation and to ensure a robust and representative product is developed.

\section{Conclusions}

It is something of a contradiction that the global-scale estimation of surface fluxes is both straightforward and extremely challenging at the same time. It is more straightforward than ever due to the availability of needed forcing data from various sources, such as numerical weather prediction or other operational products, as well as the increased development of global satellite-based data sets. However, the comparative ease with which products can be developed belies the difficulties in actually developing robust and coherent simulations. Uncertainties in the use of internally inconsistent forcing data, the influence of untested model parameterisations over different land surface and climate types, violation of model assumptions in their graduation from the local scale to global scale and the perennial question on how to best evaluate model output all seek to confound global flux efforts.

The evaluation of four process-based evaporation models as part of the GEWEX LandFlux project undertaken here over a range of biome types and climate zones, highlighted the variable performance and verified the sentiment that no single model is able to consistently outperform any other. While individual model results at the tower scale allowed for a relative performance ranking, the overall model errors when considered globally were high. Of those models assessed here and being considered as potential candidates for a GEWEX LandFlux product, PT-JPL and GLEAM represent the most likely schemes for providing consistent simulation response over a range of biome and climate types. In a challenge for the development of more accurate global flux products, application of gridded data reduces the performance of all models, even if the overall performance ranking does not change between simulation runs. Such a response has obvious implications when model simulations at the continental and global scales are increasingly required in many applications and where not only the forcing data have large uncertainties, but also the underlying assumptions of the models themselves are likely to be questioned. Further investigations on the reasons for such variable performance and ways to offset the inherent uncertainties in global forcing are required. Additional research is also needed to improve the structure and parameterisation of some of these candidate models, to understand model sensitivities to forcing (by conducting a thorough sensitivity analysis) and to develop and implement an appropriate ensemble modelling and merging technique that takes advantage of individual model performance over defined regions. Further detailed comparisons against estimates from more complex modelling systems, such as reanalysis and numerical weather prediction models, are needed to provide greater context and additional benchmarking metrics to guide future investigations. 


\section{Appendix A: Description of tower locations}

Table A1. Selected eddy-covariance and their attributes. Further details and information on individual tower sites can be found via the FLUXNET data portal (http://fluxnet.fluxdata.org/).

\begin{tabular}{|c|c|c|c|c|c|c|c|c|c|}
\hline Site-ID & Country & Lat. & Lon. & $\begin{array}{r}\text { Ground } \\
\text { elev. } \\
\text { (m a.s.1.) }\end{array}$ & $\begin{array}{l}\text { Tower } \\
\text { height } \\
(\mathrm{m})\end{array}$ & IGBP & $\begin{array}{l}\text { Climate } \\
\text { class }\end{array}$ & $\begin{array}{l}\text { Climate } \\
\text { zone }\end{array}$ & Reference \\
\hline BW-Ma1 & Botswana & -19.9 & 23.6 & 947 & 12.6 & WSA & BSh & Dry & Veenendaal et al. (2004) \\
\hline CA-Ca1 & Canada & 49.9 & -125.3 & 324 & 43 & ENF & $\mathrm{Cfb}$ & Temperate & Humphreys et al. (2006) \\
\hline CA-Mer & Canada & 45.4 & -75.5 & 68 & 3 & WET & $\mathrm{Dfb}$ & Temperate-continental & Kross et al. (2013) \\
\hline CA-Oas & Canada & 53.6 & -106.2 & 594 & 39 & DBF & Dfc & Boreal & Fu et al. (2014) \\
\hline CA-Obs & Canada & 54.0 & -105.1 & 593 & 25 & ENF & Dfc & Boreal & Fu et al. (2014) \\
\hline CA-Ojp & Canada & 53.9 & -104.7 & 517 & 28 & ENF & Dfc & Boreal & Hilton et al. (2014) \\
\hline CA-Qfo & Canada & 49.7 & -74.3 & 389 & 25 & ENF & Dfc & Boreal & Flanagan et al. (2012) \\
\hline CN-Do2 & China & 31.6 & 121.9 & 4 & 5 & WET & $\mathrm{Cfa}$ & Sub-tropical & Yan et al. (2008) \\
\hline DE-Geb & Germany & 51.1 & 10.9 & 159 & 6 & $\mathrm{CRO}$ & $\mathrm{Cfb}$ & Temperate & Smith et al. (2010) \\
\hline DE-Hai & Germany & 51.1 & 10.5 & 458 & 43.5 & $\mathrm{DBF}$ & $\mathrm{Cfb}$ & Temperate & Rebmann et al. (2005) \\
\hline DE-Kli & Germany & 50.9 & 13.5 & 480 & 3.5 & CRO & $\mathrm{Cfb}$ & Temperate & Smith et al. (2010) \\
\hline DE-Meh & Germany & 51.3 & 10.7 & 289 & 3 & GRA & $\mathrm{Cfb}$ & Temperate & Don et al. (2009) \\
\hline DE-Tha & Germany & 51.0 & 13.6 & 387 & 42 & ENF & $\mathrm{Cfb}$ & Temperate & Delpierre et al. (2009) \\
\hline DE-Wet & Germany & 50.5 & 11.5 & 789 & 27 & ENF & $\mathrm{Cfb}$ & Temperate & Richardson et al. (2010) \\
\hline FR-LBr & France & 44.7 & -0.8 & 71 & 41 & ENF & $\mathrm{Cfb}$ & Temperate & Göckede et al. (2008) \\
\hline FR-Lam & France & 43.5 & 1.2 & 182 & 3.65 & $\mathrm{CRO}$ & $\mathrm{Cfb}$ & Temperate & Merlin et al. (2011) \\
\hline FR-Pue & France & 43.7 & 3.6 & 271 & 13 & $\mathrm{EBF}$ & Csa & Sub-tropical & Soudani et al. (2014) \\
\hline IL-Yat & Israel & 31.3 & 35.1 & 654 & 18 & ENF & $\mathrm{BSh}$ & Dry & Sprintsin et al. (2011) \\
\hline IT-BCi & Italy & 40.5 & 15.0 & 9 & 2 & CRO & Csa & Sub-tropical & Reichstein et al. (2003) \\
\hline IT-Col & Italy & 41.8 & 13.6 & 1534 & 25 & DBF & $\mathrm{Cfa}$ & Sub-tropical & Chiti et al. (2010) \\
\hline IT-Lav & Italy & 46.0 & 11.3 & 1367 & 33 & ENF & $\mathrm{Cfb}$ & Temperate & Stoy et al. (2013) \\
\hline IT-MBo & Italy & 46.0 & 11.0 & 1563 & 2.5 & GRA & $\mathrm{Cfb}$ & Temperate & Gamon et al. (2010) \\
\hline IT-Noe & Italy & 40.6 & 8.2 & 27 & 3.6 & $\mathrm{CSH}$ & Csa & Sub-tropical & Carvalhais et al. (2010) \\
\hline IT-Ro1 & Italy & 42.4 & 11.9 & 174 & 20 & DBF & Csa & Sub-tropical & Chiti et al. (2010) \\
\hline JP-Tom & Japan & 42.7 & 141.5 & 133 & 42 & $\mathrm{MF}$ & $\mathrm{Dfb}$ & Temperate-continental & Saigusa et al. (2010) \\
\hline NL-Ca1 & Netherlands & 52.0 & 4.9 & -1 & 5 & GRA & $\mathrm{Cfb}$ & Temperate & Gioli et al. (2004) \\
\hline NL-Loo & Netherlands & 52.2 & 5.7 & 34 & 27 & ENF & $\mathrm{Cfb}$ & Temperate & Sulkava et al. (2011) \\
\hline PT-Mi2 & Portugal & 38.5 & -8.0 & 191 & 2.5 & GRA & Csa & Sub-tropical & Gilmanov et al. (2007) \\
\hline RU-Fyo & Russia & 56.5 & 32.9 & 274 & 29 & ENF & $\mathrm{Dfb}$ & Temperate-continental & Smith et al. (2010) \\
\hline SE-Nor & Sweden & 60.1 & 17.5 & 35 & 103 & ENF & Dfb & Temperate-continental & Zierl et al. (2007) \\
\hline US-ARM & USA & 36.6 & -97.5 & 318 & 60 & CRO & $\mathrm{Cfa}$ & Sub-tropical & Lokupitiya et al. (2009) \\
\hline US-Aud & USA & 31.6 & -110.5 & 1474 & 4 & GRA & BSk & Dry & Horn and Schulz (2011) \\
\hline US-Bkg & USA & 44.3 & -96.8 & 496 & 4 & GRA & Dfa & Temperate-continental & Hollinger et al. (2010) \\
\hline US-Bo1 & USA & 40.0 & -88.3 & 218 & 10 & CRO & Dfa & Temperate-continental & Hollinger et al. (2010) \\
\hline US-Bo2 & USA & 40.0 & -88.3 & 220 & 10 & CRO & Dfa & Temperate-continental & Hollinger et al. (2010) \\
\hline US-CaV & USA & 39.1 & -79.4 & 993 & 4 & GRA & $\mathrm{Cfb}$ & Temperate & Hollinger et al. (2010) \\
\hline US-FPe & USA & 48.3 & -105.1 & 632 & 3.5 & GRA & BSk & Dry & Horn and Schulz (2011) \\
\hline US-Goo & USA & 34.3 & -89.9 & 94 & 4 & GRA & $\mathrm{Cfa}$ & Sub-tropical & Hollinger et al. (2010) \\
\hline US-MMS & USA & 39.3 & -86.4 & 290 & 48 & DBF & $\mathrm{Cfa}$ & Sub-tropical & Dragoni et al. (2011) \\
\hline US-MOz & USA & 38.7 & -92.2 & 238 & 30 & $\mathrm{DBF}$ & $\mathrm{Cfa}$ & Sub-tropical & Hollinger et al. (2010) \\
\hline US-NR1 & USA & 40.0 & -105.5 & 3053 & 26 & ENF & $\mathrm{Dfc}$ & Boreal & Hilton et al. (2014) \\
\hline US-SRM & USA & 31.8 & -110.9 & 1120 & 6.4 & WSA & BSk & Dry & Cavanaugh et al. (2011) \\
\hline US-WCr & USA & 45.8 & -90.1 & 524 & 30 & DBF & $\mathrm{Dfb}$ & Temperate-continental & Curtis et al. (2002) \\
\hline US-Wkg & USA & 31.7 & -109.9 & 1522 & 6.4 & GRA & BSk & Dry & Scott $(2010)$ \\
\hline US-Wrc & USA & 45.8 & -122.0 & 391 & 85 & ENF & $\mathrm{Csb}$ & Temperate & Wharton et al. (2009) \\
\hline
\end{tabular}




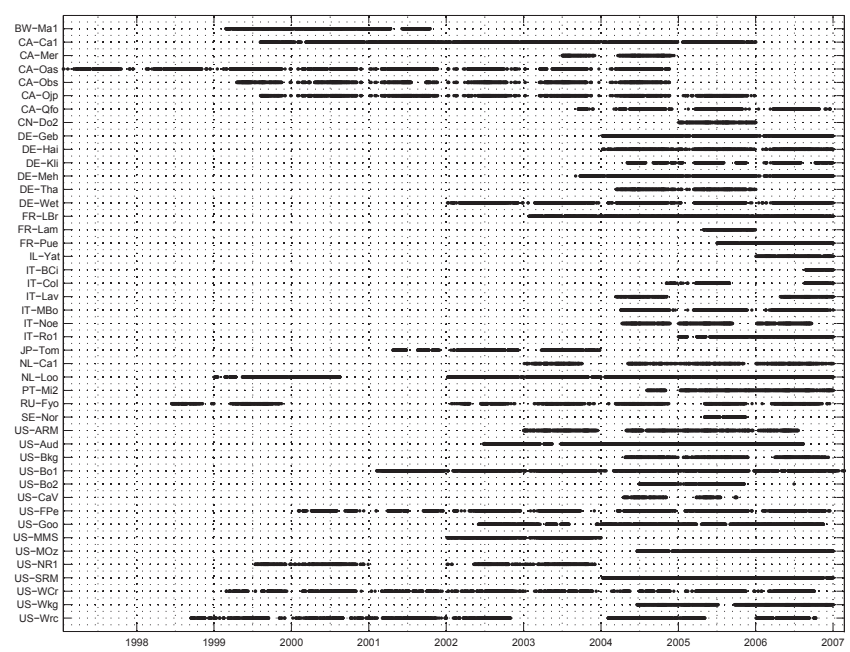

Figure A1. Temporal duration of the eddy-covariance-based flux and tower meteorological observations for each of the 45 sites used in this study.
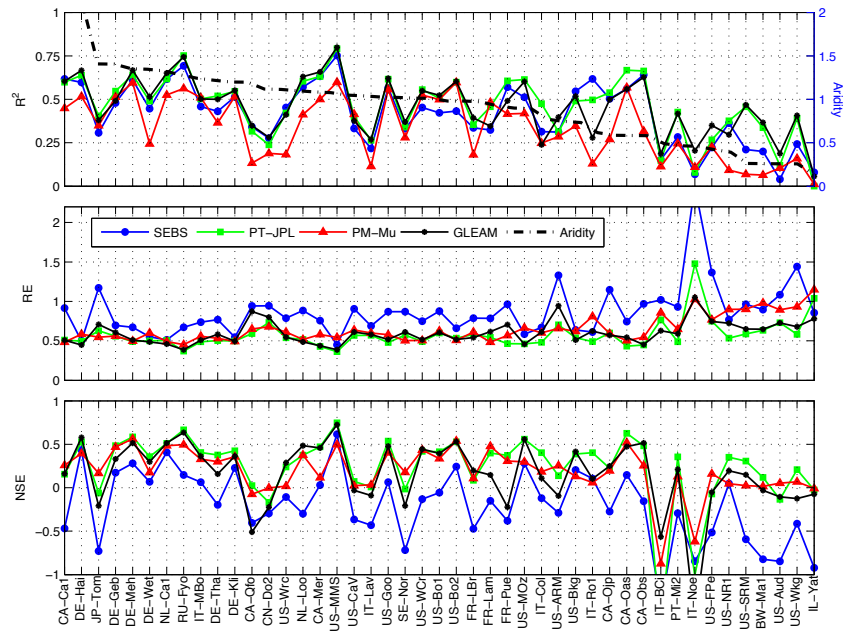

Figure A2. Comparison of the performance skill of the models in reproducing evaporation for the grid-based analyses. $R^{2}$ is the coefficient of determination, RE is relative error (lower is better) and NSE is the Nash-Sutcliffe efficiency (higher is better). Towers are arranged from left to right based on an aridity index (secondary $y$ axis). 


\section{Code availability}

The PM-Mu, SEBS and PT-JPL models were coded in MATLAB as part of the GEWEX LandFlux and WACMOS-ET projects, in discussion with (but independent of) the principal model authors, as referenced in the relevant publications. The GLEAM model was developed in MATLAB by Diego Miralles and Brecht Martens. All model code can be made available upon an emailed request to hydrology @ kaust.edu.sa, including a brief description of the intended purpose and application.

\section{Data availability}

Evaporation model output presented here for both the gridded and tower-based analyses can be provided upon an emailed request to hydrology@kaust.edu.sa. The request should include a brief description of the intended purpose and application of the model data. Further details can be found at http://hydrology.kaust.edu.sa/landflux.

Acknowledgements. Research reported in this publication was supported by the King Abdullah University of Science and Technology (KAUST). D. G. Miralles acknowledges the financial support from The Netherlands Organization for Scientific Research through grant 863.14.004. We appreciate the support of the ESA funded WACMOS-ET project for both fruitful scientific discussions and guidance in ensuring complementarity of these joint efforts. We thank the FLUXNET site investigators for allowing for the use of their meteorological data. This work used eddy-covariance data acquired by the FLUXNET community and in particular by the AmeriFlux program (U.S. Department of Energy, Biological and Environmental Research, Terrestrial Carbon Program: DE-FG0204ER63917 and DE-FG02-04ER63911), AfriFlux, AsiaFlux, CarboAfrica, CarboEuropeIP, CarboItaly, CarboMont, ChinaFlux, Fluxnet-Canada (supported by CFCAS, NSERC, BIOCAP, Environment Canada, and NRCan), GreenGrass, KoFlux, LBA, NECC, TCOS-Siberia, USCCC. We acknowledge the financial support to the eddy-covariance data harmonisation provided by CarboEuropeIP, FAO-GTOS-TCO, iLEAPS, Max Planck Institute for Biogeochemistry, National Science Foundation, University of Tuscia, Université Laval and Environment Canada and US Department of Energy and the database development and technical support from Berkeley Water Centre, Lawrence Berkeley National Laboratory, Microsoft Research eScience, Oak Ridge National Laboratory, University of California - Berkeley, University of Virginia.

Edited by: J. Kala

\section{References}

Adler, R. F., Huffman, G. J., Chang, A., Ferraro, R., Xie, P. P., Janowiak, J., Rudolf, B., Schneider, U., Curtis, S., Bolvin, D., Gruber, A., Susskind, J., Arkin, P., and Nelkin, E.: The version2 global precipitation climatology project (GPCP) monthly pre- cipitation analysis (1979-present), J. Hydrometeorol., 4, 11471167, 2003.

Allen, R. G.: Using the FAO-56 dual crop coefficient method over an irrigated region as part of an evapotranspiration intercomparison study, J. Hydrol., 229, 27-41, 2000.

Allen, R. G., Tasumi, M., and Trezza, R.: Satellite-Based Energy Balance for Mapping Evapotranspiration with Internalized Calibration (METRIC)-Model, J. Irrig. Drain. E., 133, 380-394, 2007.

Armstrong, R. L., Brodzik, M. J., Knowles, K., and Savoie, M.: Global monthly EASE-Grid snow water equivalent climatology, National Snow and Ice Data Center, Digital media, Boulder, CO, USA, 2005.

Badgley, G., Fisher, J. B., Jiménez, C., Tu, K. P., and Vinukollu, R.: On uncertainty in global terrestrial evapotranspiration estimates from choice of input forcing datasets, J. Hydrometeorol., 16, 1449-1455, doi:10.1175/JHM-D-14-0040.1, 2015.

Baldocchi, D., Falge, E., Gu, L., Olson, R., Hollinger, D., Running, S., Anthoni, P., Bernhofer, C., Davis, K., Evans, R., Fuentes, J., Goldstein, A., Katul, G., Law, B., Lee, X., Malhi, Y., Meyers, T., Munger, W., Oechel, W., Paw, K. T., Pilegaard, K., Schmid, H. P., Valentini, R., Verma, S., Vesala, T., Wilson, K., and Wofsy, S.: FLUXNET: A New Tool to Study the Temporal and Spatial Variability of Ecosystem-Scale Carbon Dioxide, Water Vapor, and Energy Flux Densities, B. Am. Meteorol. Soc., 82, 24152434, 2001.

Bastiaanssen, W. G. M., Menenti, M., Feddes, R. A., and Holtslag, A. A. M.: A remote sensing surface energy balance algorithm for land (SEBAL). 1. Formulation, J. Hydrol., 212-213, 198-212, 1998.

Bos, M. G., Kselik, R. A. L., Allen, R. G., and Molden, D. J.: Water Requirements for Irrigation and the Environment, Springer, Dordrecht, the Netherlands, 2008.

Bouchet, R. J.: Evapotranspiration réelle et potentielle, signification climatique. General Assembly Berkeley, International Association for Hydrological Sciences, Gentbrugge, Belgium, 62, 134-142, 1963.

Brutsaert, W.: Evaporation Into the Atmosphere: theory, history, and applications, Reidel Publishing, Dordrecht, the Netherlands, 1982.

Brutsaert, W.: Hydrology : An Introduction, Cambridge University Press, Cambridge, UK, 2005.

Brutsaert, W. and Stricker, H.: An advection-aridity approach to estimate actual regional evapotranspiration, Water Resour. Res., 15, 443-450, 1979.

Carvalhais, N., Reichstein, M., Collatz, G. J., Mahecha, M. D., Migliavacca, M., Neigh, C. S. R., Tomelleri, E., Benali, A. A., Papale, D., and Seixas, J.: Deciphering the components of regional net ecosystem fluxes following a bottom-up approach for the Iberian Peninsula, Biogeosciences, 7, 3707-3729, doi:10.5194/bg-7-3707-2010, 2010.

Cavanaugh, M. L., Kurc, S. A., and Scott, R. L.: Evapotranspiration partitioning in semiarid shrubland ecosystems: a two-site evaluation of soil moisture control on transpiration, Ecohydrology, 4 , 671-681, 2011.

Chahine, M. T.: The hydrological cycle and its influence on climate, Nature, 359, 373-380, 1992.

Chen, X., Su, Z., Ma, Y., Yang, K., Wen, J., and Zhang, Y.: An Improvement of Roughness Height Parameterization of the Sur- 
face Energy Balance System (SEBS) over the Tibetan Plateau, J. Appl. Meteorol. Clim., 52, 607-622, 2012.

Chiti, T., Papale, D., Smith, P., Dalmonech, D., Matteucci, G., Yeluripati, J., Rodeghiero, M., and Valentini, R.: Predicting changes in soil organic carbon in mediterranean and alpine forests during the Kyoto Protocol commitment periods using the CENTURY model, Soil Use Manage., 26, 475-484, 2010.

Coccia, G., Siemann, A., Pan, M., and Wood, E. F.: Creating consistent datasets by combining remotely-sensed data and land surface model estimates through Bayesian uncertainty post-processing: the case of Land Surface Temperature from HIRS, Remote Sens. Environ., 170, 290-305, doi:10.1016/j.rse.2015.09.010, 2015.

Curtis, P. S., Hanson, P. J., Bolstad, P., Barford, C., Randolph, J. C., Schmid, H. P., and Wilson, K. B.: Biometric and eddy-covariance based estimates of annual carbon storage in five eastern North American deciduous forests, Agr. Forest Meteorol., 113, 3-19, 2002.

Delpierre, N., Soudani, K., Francois, C., Köstner, B., Pontailler, J. Y., Nikinmaa, E., Misson, L., Aubinet, M., Bernhofer, C., and Granier, A.: Exceptional carbon uptake in European forests during the warm spring of 2007: a data-model analysis, Glob. Change Biol., 15, 1455-1474, 2009.

Don, A., Rebmann, C., Kolle, O., Scherer-Lorenzen, M., and Schulze, E. D.: Impact of afforestation-associated management changes on the carbon balance of grassland, Glob. Change Biol., 15, 1990-2002, 2009.

Douville, H., Ribes, A., Decharme, B., Alkama, R., and Sheffield, J.: Anthropogenic influence on multidecadal changes in reconstructed global evapotranspiration, Nature Clim. Change, 3, 5962, 2013.

Dragoni, D., Schmid, H. P., Wayson, C. A., Potter, H., Grimmond, C. S. B., and Randolph, J. C.: Evidence of increased net ecosystem productivity associated with a longer vegetated season in a deciduous forest in south-central Indiana, USA, Glob. Change Biol., 17, 886-897, 2011.

Ershadi, A., McCabe, M. F., Evans, J. P., Mariethoz, G., and Kavetski, D.: A Bayesian analysis of sensible heat flux estimation: Quantifying uncertainty in meteorological forcing to improve model prediction, Water Resour. Res., 49, 2343-2358, 2013.

Ershadi, A., McCabe, M. F., Evans, J. P., Chaney, N. W., and Wood, E. F.: Multi-site evaluation of terrestrial evaporation models using FLUXNET data, Agr. Forest Meteorol., 187, 46-61, 2014.

Ershadi, A., McCabe, M. F., Evans, J. P., and Wood, E. F.: Impact of model structure and parameterization on Penman-Monteith type evaporation models, J. Hydrol., 525, 521-535, 2015.

Famiglietti, J. S., Lo, M., Ho, S. L., Bethune, J., Anderson, K. J., Syed, T. H., Swenson, S. C., de Linage, C. R., and Rodell, M.: Satellites measure recent rates of groundwater depletion in California's Central Valley, Geophys. Res. Lett., 38, L03403, doi:10.1029/2010GL046442, 2011.

Fisher, J. B., Tu, K. P., and Baldocchi, D. D.: Global estimates of the land-atmosphere water flux based on monthly AVHRR and ISLSCP-II data, validated at 16 FLUXNET sites, Remote Sens. Environ., 112, 901-919, 2008.

Flanagan, L. B., Cai, T., Black, T. A., Barr, A. G., McCaughey, J. H., and Margolis, H. A.: Measuring and modeling ecosystem photosynthesis and the carbon isotope composition of ecosystemrespired $\mathrm{CO}_{2}$ in three boreal coniferous forests, Agr. Forest Meteorol., 153, 165-176, 2012.
Fu, D., Chen, B., Zhang, H., Wang, J., Black, T. A., Amiro, B. D., Bohrer, G., Bolstad, P., Coulter, R., and Rahman, A. F.: Estimating landscape net ecosystem exchange at high spatial-temporal resolution based on Landsat data, an improved upscaling model framework, and eddy covariance flux measurements, Remote Sens. Environ., 141, 90-104, 2014.

Gamon, J. A., Coburn, C., Flanagan, L. B., Huemmrich, K. F., Kiddle, C., Sanchez-Azofeifa, G. A., Thayer, D. R., Vescovo, L., Gianelle, D., and Sims, D. A.: SpecNet revisited: bridging flux and remote sensing communities, Can. J. Remote Sens., 36, S376S390, 2010.

Gash, J. H.: An analytical model of rainfall interception by forests quarterly, Q. J. Roy. Meteor. Soc., 105, 43-45, 1979.

Gilmanov, T., Soussana, J., Aires, L., Allard, V., Ammann, C., Balzarolo, M., Barcza, Z., Bernhofer, C., Campbell, C., Cernusca, A., Cescatti, A., Clifton-Brown, J., Dirks, B., Dore, S., Eugster, W., Fuhrer, J., Gimeno, C., Gruenwald, T., Haszpra, L., Hensen, A., Ibrom, A., Jacobs, A., Jones, M., Lanigan, G., Laurila, T., Lohila, A., Manca, G., Marcolla, B., Nagy, Z., Pilegaard, K., Pinter, K., Pio, C., Raschi, A., Rogiers, N., Sanz, M., Stefani, P., Sutton, M., Tuba, Z., Valentini, R., Williams, M., and Wohlfahrt, G.: Partitioning European grassland net ecosystem $\mathrm{CO}_{2}$ exchange into gross primary productivity and ecosystem respiration using light response function analysis, Agr. Ecosyst. Environ., 121, 93-120, 2007.

Gioli, B., Miglietta, F., De Martino, B., Hutjes, R. W. A., Dolman, H. A. J., Lindroth, A., Schumacher, M., Sanz, M. J., Manca, G., and Peressotti, A.: Comparison between tower and aircraft-based eddy covariance fluxes in five European regions, Agr. Forest Meteorol., 127, 1-16, 2004.

Göckede, M., Foken, T., Aubinet, M., Aurela, M., Banza, J., Bernhofer, C., Bonnefond, J. M., Brunet, Y., Carrara, A., Clement, R., Dellwik, E., Elbers, J., Eugster, W., Fuhrer, J., Granier, A., Grünwald, T., Heinesch, B., Janssens, I. A., Knohl, A., Koeble, R., Laurila, T., Longdoz, B., Manca, G., Marek, M., Markkanen, T., Mateus, J., Matteucci, G., Mauder, M., Migliavacca, M., Minerbi, S., Moncrieff, J., Montagnani, L., Moors, E., Ourcival, J.-M., Papale, D., Pereira, J., Pilegaard, K., Pita, G., Rambal, S., Rebmann, C., Rodrigues, A., Rotenberg, E., Sanz, M. J., Sedlak, P., Seufert, G., Siebicke, L., Soussana, J. F., Valentini, R., Vesala, T., Verbeeck, H., and Yakir, D.: Quality control of CarboEurope flux data - Part 1: Coupling footprint analyses with flux data quality assessment to evaluate sites in forest ecosystems, Biogeosciences, 5, 433-450, doi:10.5194/bg-5-433-2008, 2008.

Granger, R. J.: Satellite-derived estimates of evapotranspiration in the Gediz basin, J. Hydrol., 229, 70-76, 2000.

Greve, P., Orlowsky, B., Mueller, B., Sheffield, J., Reichstein, M., and Seneviratne, S. I.: Global assessment of trends in wetting and drying over land, Nat. Geosci., 7, 716-721, 2014.

Guillod, B. P., Orlowsky, B., Miralles, D. G., Teuling, A. J., and Seneviratne, S. I.: Reconciling spatial and temporal soil moisture effects on afternoon rainfall, Nat. Commun., 6, 6443, doi:10.1038/ncomms7443, 2015.

Hansen, M. C., Townshend, J. R. G., DeFries, R. S., and Carroll, M.: Estimation of tree cover using MODIS data at global, continental and regional/local scales, Int. J. Remote Sens., 26, 4359-4380, 2005. 
Harman, I.: The Role of Roughness Sublayer Dynamics Within Surface Exchange Schemes, Bound.-Lay. Meteorol., 142, 1-20, 2012.

Hilton, T. W., Davis, K. J., and Keller, K.: Evaluating terrestrial $\mathrm{CO}_{2}$ flux diagnoses and uncertainties from a simple land surface model and its residuals, Biogeosciences, 11, 217-235, doi:10.5194/bg-11-217-2014, 2014.

Hirschi, M., Seneviratne, S. I., Alexandrov, V., Boberg, F., Boroneant, C., Christensen, O. B., Formayer, H., Orlowsky, B., and Stepanek, P.: Observational evidence for soil-moisture impact on hot extremes in southeastern Europe, Nat. Geosci., 4, 17-21, 2011.

Hoeting, J. A., Madigan, D., Raftery, A. E., and Volinsky, C. T.: Bayesian Model Averaging: A Tutorial, Stat. Sci., 14, 382-401, 1999.

Hollinger, D. Y., Ollinger, S. V., Richardson, A. D., Meyers, T. P., Dail, D. B., Martin, M. E., Scott, N. A., Arkebauer, T. J., Baldocchi, D. D., and Clark, K. L.: Albedo estimates for land surface models and support for a new paradigm based on foliage nitrogen concentration, Glob. Change Biol., 16, 696-710, 2010.

Horn, J. E. and Schulz, K.: Identification of a general light use efficiency model for gross primary production, Biogeosciences, 8 , 999-1021, doi:10.5194/bg-8-999-2011, 2011.

Houborg, R., McCabe, M. F., and Gao, F.: A Spatio-Temporal Enhancement Method for medium resolution LAI (STEM-LAI), Int. J. Appl. Earth Obs., 47, 15-29, 2016.

Huffman, G. J., Adler, R. F., Rudolph, B., Schneider, U., and Keehn, P.: Global precipitation estimates based on a technique for combining satellite-based estimates, rain gauge analysis, and NWP model precipitation information, J. Climate, 8, 1284-1295, 1995.

Humphreys, E. R., Black, T. A., Morgenstern, K., Cai, T., Drewitt, G. B., Nesic, Z., and Trofymow, J. A.: Carbon dioxide fluxes in coastal Douglas-fir stands at different stages of development after clearcut harvesting, Agr. Forest Meteorol., 140, 6-22, 2006.

Jiménez, C., Prigent, C., Mueller, B., Seneviratne, S. I., McCabe, M. F., Wood, E. F., Rossow, W. B., Balsamo, G., Betts, A. K., Dirmeyer, P. A., Fisher, J. B., Jung, M., Kanamitsu, M., Reichle, R. H., Reichstein, M., Rodell, M., Sheffield, J., Tu, K., and Wang, K.: Global intercomparison of 12 land surface heat flux estimates, J. Geophys. Res., 116, D02102, doi:10.1029/2010JD014545, 2011.

Jiménez-Muñoz, J., Sobrino, J., Plaza, A., Guanter, L., Moreno, J., and Martinez, P.: Comparison Between Fractional Vegetation Cover Retrievals from Vegetation Indices and Spectral Mixture Analysis: Case Study of PROBA/CHRIS Data Over an Agricultural Area, Sensors, 9, 768-793, 2009.

Jung, M., Reichstein, M., Ciais, P., Seneviratne, S. I., Sheffield, J., Goulden, M. L., Bonan, G., Cescatti, A., Chen, J., and de Jeu, R.: Recent decline in the global land evapotranspiration trend due to limited moisture supply, Nature, 467, 951-954, 2010.

Kross, A., Seaquist, J. W., Roulet, N. T., Fernandes, R., and Sonnentag, O.: Estimating carbon dioxide exchange rates at contrasting northern peatlands using MODIS satellite data, Remote Sens. Environ., 137, 234-243, 2013.

Kustas, W. P., Perry, E. M., Doraiswamy, P. C., and Moran, M. S.: Using satellite remote sensing to extrapolate evapotranspiration in time and space over a semiarid rangeland, Remote Sens. Environ., 49, 275-286, 1994.
Liu, Y. Y., de Jeu, R. A. M., McCabe, M. F., Evans, J. P., and van Dijk, A. I. J. M.: Global long-term passive microwave satellitebased retrievals of vegetation optical depth, Geophys. Res. Lett., 38, L18402, doi:10.1029/2011GL048684, 2011a.

Liu, Y. Y., Parinussa, R. M., Dorigo, W. A., De Jeu, R. A. M., Wagner, W., van Dijk, A. I. J. M., McCabe, M. F., and Evans, J. P.: Developing an improved soil moisture dataset by blending passive and active microwave satellite-based retrievals, Hydrol. Earth Syst. Sci., 15, 425-436, doi:10.5194/hess-15-425-2011, 2011 b.

Liu, Y. Y., Dorigo, W. A., Parinussa, R. M., De Jeu, R. A. M., Wagner, W., McCabe, M. F., Evans, J. P., and Van Dijk, A. I. J. M.: Trend-preserving blending of passive and active microwave soil moisture retrievals, Remote Sens. Environ., 123, 280-297, 2012.

Liu, Y. Y., van Dijk, A. I. J. M., McCabe, M. F., Evans, J. P., and de Jeu, R. A. M.: Global vegetation biomass change (1988-2008) and attribution to environmental and human drivers, Global Ecol. Biogeogr., 22, 692-705, 2013.

Lokupitiya, E., Denning, S., Paustian, K., Baker, I., Schaefer, K., Verma, S., Meyers, T., Bernacchi, C. J., Suyker, A., and Fischer, M.: Incorporation of crop phenology in Simple Biosphere Model (SiBcrop) to improve land-atmosphere carbon exchanges from croplands, Biogeosciences, 6, 969-986, doi:10.5194/bg-6-9692009, 2009.

Luojus, K., Pulliainen, J., Takala, M., Lemmetyinen, J., Derksen, C., and Wang, L.: Snow water equivalent (SWE) product guide, Global Snow Monitoring for Climate Research, European Space Agency Study Contract Report Esrin Contract 21703/08/IEC), available at: http://www.globsnow.info/docs/GlobSnow_2_ Final_Report_release.pdf (last access: 25 January 2016), 2010.

Mach, D. M., Christian, H. J., Blakeslee, R. J., Boccippio, D. J., Goodman, S. J., and Boeck, W. L.: Performance assessment of the optical transient detector and lightning imaging sensor, J. Geophys. Res.-Atmos. (1984-2012), 112, D09210, doi:10.1029/2006JD007787, 2007.

McCabe, M. F. and Wood, E. F.: Scale influences on the remote estimation of evapotranspiration using multiple satellite sensors, Remote Sens. Environ., 105, 271-285, 2006.

McCabe, M. F., Wood, E. F., Wójcik, R., Pan, M., Sheffield, J., Gao, H., and Su, H.: Hydrological consistency using multi-sensor remote sensing data for water and energy cycle studies, Remote Sens. Environ., 112, 430-444, 2008.

Merlin, O., Al Bitar, A., Rivalland, V., Béziat, P., Ceschia, E., and Dedieu, G.: An analytical model of evaporation efficiency for unsaturated soil surfaces with an arbitrary thickness, J. Appl. Meteorol. Clim., 50, 457-471, 2011.

Michel, D., Jiménez, C., Miralles, D. G., Jung, M., Hirschi, M., Ershadi, A., Martens, B., McCabe, M. F., Fisher, J. B., Mu, Q., Seneviratne, S. I., Wood, E. F., and Fernández-Prieto, D.: The WACMOS-ET project - Part 1: Tower-scale evaluation of four remote sensing-based evapotranspiration algorithms, Hydrol. Earth Syst. Sci. Discuss., 12, 10739-10787, doi:10.5194/hessd12-10739-2015, 2015.

Miralles, D. G., Gash, J. H., Holmes, T. R. H., de Jeu, R. A. M., and Dolman, A.: Global canopy interception from satellite observations, J. Geophys. Res., 115, D16122, doi:10.1029/2009JD013530, 2010.

Miralles, D. G., De Jeu, R. A. M., Gash, J. H., Holmes, T. R. H., and Dolman, A. J.: Magnitude and variability of land evaporation and 
its components at the global scale, Hydrol. Earth Syst. Sci., 15, 967-981, doi:10.5194/hess-15-967-2011, 2011a.

Miralles, D. G., Holmes, T. R. H., De Jeu, R. A. M., Gash, J. H., Meesters, A. G. C. A., and Dolman, A. J.: Global land-surface evaporation estimated from satellite-based observations, Hydrol. Earth Syst. Sci., 15, 453-469, doi:10.5194/hess-15-453-2011, 2011 b.

Miralles, D. G., Teuling, A. J., van Heerwaarden, C. C., and de Arellano, J. V.-G.: Mega-heatwave temperatures due to combined soil desiccation and atmospheric heat accumulation, Nat. Geosci., 7, 345-349, 2014a.

Miralles, D. G., van den Berg, M. J., Gash, J. H., Parinussa, R. M., de Jeu, R. A. M., Beck, H. E., Holmes, T. R. H., Jiménez, C., Verhoest, N. E. C., and Dorigo, W. A.: El Niño-La Niña cycle and recent trends in continental evaporation, Nature Climate Change, 4, 122-126, 2014b.

Miralles, D. G., Jiménez, C., Jung, M., Michel, D., Ershadi, A., McCabe, M. F., Hirschi, M., Martens, B., Dolman, A. J., Fisher, J. B., Mu, Q., Seneviratne, S. I., Wood, E. F., and FernaìndezPrieto, D.: The WACMOS-ET project - Part 2: Evaluation of global terrestrial evaporation data sets, Hydrol. Earth Syst. Sci. Discuss., 12, 10651-10700, doi:10.5194/hessd-12-10651-2015, 2015.

Monteith, J. L.: Evaporation and environment, Symp. Soc. Exp. Biol., 19, 205-234, 1965.

Mu, Q., Heinsch, F. A., Zhao, M., and Running, S. W.: Development of a global evapotranspiration algorithm based on MODIS and global meteorology data, Remote Sens. Environ., 111, 519-536, 2007.

Mu, Q., Zhao, M., and Running, S. W.: Improvements to a MODIS global terrestrial evapotranspiration algorithm, Remote Sens. Environ., 115, 1781-1800, 2011.

Mu, Q., Zhao, M., Kimball, J. S., McDowell, N. G., and Running, S. W.: A Remotely Sensed Global Terrestrial Drought Severity Index, B. Am. Meteorol. Soc., 94, 83-98, 2012.

Mu, Q., Zhao, M., and Running, S. W.: MODIS Global Terrestrial Evapotranspiration (ET) Product (NASA MOD16A2/A3), Algorithm Theoretical Basis Document, Collection, 5, The University of Montana, Missoula, MT, USA, available at: http://www.ntsg. umt.edu/node/801 (last access: 25 January 2016), 2013.

Mueller, B., Seneviratne, S. I., Jimenez, C., Corti, T., Hirschi, M., Balsamo, G., Ciais, P., Dirmeyer, P., Fisher, J. B., Guo, Z., Jung, M., Maignan, F., McCabe, M. F., Reichle, R., Reichstein, M., Rodell, M., Sheffield, J., Teuling, A. J., Wang, K., Wood, E. F., and Zhang, Y.: Evaluation of global observations-based evapotranspiration datasets and IPCC AR4 simulations, Geophys. Res. Lett., 38, L06402, doi:10.1029/2010GL046230, 2011.

Mueller, B., Hirschi, M., Jimenez, C., Ciais, P., Dirmeyer, P. A., Dolman, A. J., Fisher, J. B., Jung, M., Ludwig, F., Maignan, F., Miralles, D. G., McCabe, M. F., Reichstein, M., Sheffield, J., Wang, K., Wood, E. F., Zhang, Y., and Seneviratne, S. I.: Benchmark products for land evapotranspiration: LandFluxEVAL multi-data set synthesis, Hydrol. Earth Syst. Sci., 17, 3707-3720, doi:10.5194/hess-17-3707-2013, 2013.

Nash, J. E. and Sutcliffe, J. V.: River flow forecasting through conceptual models: Part I - a discussion of principles, J. Hydrol., 10, 282-290, 1970.

Nesbitt, S. W., Zipser, E. J., and Kummerow, C. D.: An examination of version-5 rainfall estimates from the TRMM Microwave
Imager, precipitation radar, and rain gauges on global, regional, and storm scales, J. Appl. Meteorol., 43, 1016-1036, 2004.

Norman, J. M., Kustas, W. P., and Humes, K. S.: Source approach for estimating soil and vegetation energy fluxes in observations of directional radiometric surface temperature, Agr. Forest Meteorol., 77, 263-293, 1995.

Otkin, J. A., Anderson, M. C., Hain, C., and Svoboda, M.: Examining the Relationship between Drought Development and Rapid Changes in the Evaporative Stress Index, J. Hydrometeorol., 15, 938-956, 2014.

Penman, H. L.: Natural Evaporation from Open Water, Bare Soil and Grass, P. Roy. Soc. Lond. A Mat., 193, 120-145, 1948.

Potter, C. S., Randerson, J. T., Field, C. B., Matson, P. A., Vitousek, P. M., Mooney, H. A., and Klooster, S. A.: Terrestrial ecosystem production: a process model based on global satellite and surface data, Global Biogeochem. Cy., 7, 811-841, 1993.

Priestley, C. H. B. and Taylor, R. J.: On the Assessment of Surface Heat Flux and Evaporation Using Large-Scale Parameters, Mon. Weather Rev., 100, 81-92, 1972.

Rebmann, C., Göckede, M., Foken, T., Aubinet, M., Aurela, M., Berbigier, P., Bernhofer, C., Buchmann, N., Carrara, A., and Cescatti, A.: Quality analysis applied on eddy covariance measurements at complex forest sites using footprint modelling, Theor. Appl. Climatol., 80, 121-141, 2005.

Reichstein, M., Rey, A., Freibauer, A., Tenhunen, J., Valentini, R., Banza, J., Casals, P., Cheng, Y., Grünzweig, J. M., and Irvine, J.: Modeling temporal and large-scale spatial variability of soil respiration from soil water availability, temperature and vegetation productivity indices, Global Biogeochem. Cy., 17, 1104, doi:10.1029/2003GB002035, 2003.

Richardson, A. D., Black, T. A., Ciais, P., Delbart, N., Friedl, M. A., Gobron, N., Hollinger, D. Y., Kutsch, W. L., Longdoz, B., and Luyssaert, S.: Influence of spring and autumn phenological transitions on forest ecosystem productivity, Philos. T. R. Soc. B, 365, 3227-3246, 2010.

Richey, A. S., Thomas, B. F., Lo, M.-H., Reager, J. T., Famiglietti, J. S., Voss, K., Swenson, S., and Rodell, M.: Quantifying renewable groundwater stress with GRACE, Water Resour. Res., 51, 52175238, doi:10.1002/2015WR017349, 2015.

Rubel, F. and Kottek, M.: Observed and projected climate shifts 1901-2100 depicted by world maps of the Köppen-Geiger climate classification, Meteorol. Z., 19, 135-141, 2010.

Saha, S., Moorthi, S., Pan, H.-L., Wu, X., Wang, J., Nadiga, S., Tripp, P., Kistler, R., Woollen, J., and Behringer, D.: The NCEP climate forecast system reanalysis, B. Am. Meteorol. Soc., 91, 1015-1057, 2010.

Sahoo, A. K., Pan, M., Troy, T. J., Vinukollu, R. K., Sheffield, J., and Wood, E. F.: Reconciling the global terrestrial water budget using satellite remote sensing, Remote Sens. Environ., 115, 1850-1865, 2011.

Saigusa, N., Ichii, K., Murakami, H., Hirata, R., Asanuma, J., Den, H., Han, S.-J., Ide, R., Li, S.-G., Ohta, T., Sasai, T., Wang, S.Q., and Yu, G.-R.: Impact of meteorological anomalies in the 2003 summer on Gross Primary Productivity in East Asia, Biogeosciences, 7, 641-655, doi:10.5194/bg-7-641-2010, 2010.

Scott, R. L.: Using watershed water balance to evaluate the accuracy of eddy covariance evaporation measurements for three semiarid ecosystems, Agr. Forest Meteorol., 150, 219-225, 2010. 
Sheffield, J., Ferguson, C. R., Troy, T. J., Wood, E. F., and McCabe, M. F.: Closing the terrestrial water budget from satellite remote sensing, Geophys. Res. Lett., 36, L07403, doi:10.1029/2009GL037338, 2009.

Sheffield, J., Wood, E. F., and Munoz-Arriola, F.: Long-term regional estimates of evapotranspiration for Mexico based on downscaled ISCCP data, J. Hydrometeorol., 11, 253-275, 2010.

Shuttleworth, W. J. and Wallace, J. S.: Evaporation from sparse crops-an energy combination theory, Q. J. Roy. Meteorol. Soc., 111, 839-855, 1985.

Simard, M., Pinto, N., Fisher, J. B., and Baccini, A.: Mapping forest canopy height globally with spaceborne lidar, J. Geophys. Res.Biogeo., 116, G04021, doi:10.1029/2011JG001708, 2011.

Smith, P., Lanigan, G., Kutsch, W. L., Buchmann, N., Eugster, W., Aubinet, M., Ceschia, E., Béziat, P., Yeluripati, J. B., and Osborne, B.: Measurements necessary for assessing the net ecosystem carbon budget of croplands, Agr. Ecosyst. Environ., 139, 302-315, 2010.

Sobrino, J. A., Jiménez-Muñoz, J. C., and Paolini, L.: Land surface temperature retrieval from LANDSAT TM 5, Remote Sens. Environ., 90, 434-440, 2004.

Soudani, K., Hmimina, G., Dufrêne, E., Berveiller, D., Delpierre, N., Ourcival, J.-M., Rambal, S., and Joffre, R.: Relationships between photochemical reflectance index and light-use efficiency in deciduous and evergreen broadleaf forests, Remote Sens. Environ., 144, 73-84, 2014.

Sprintsin, M., Cohen, S., Maseyk, K., Rotenberg, E., Grünzweig, J., Karnieli, A., Berliner, P., and Yakir, D.: Long term and seasonal courses of leaf area index in a semi-arid forest plantation, Agr. Forest Meteorol., 151, 565-574, 2011.

Stackhouse, P. W., Gupta, S. K., Cox, S. J., Zhang, T., Mikovitz, J. C., and Hinkelman, L. M.: The NASA/GEWEX surface radiation budget release 3.0: 24.5-year dataset, GEWEX News, 21, 10-12, 2011.

Stoy, P. C., Mauder, M., Foken, T., Marcolla, B., Boegh, E., Ibrom, A., Arain, M. A., Arneth, A., Aurela, M., and Bernhofer, C.: A data-driven analysis of energy balance closure across FLUXNET research sites: The role of landscape scale heterogeneity, Agr. Forest Meteorol., 171, 137-152, 2013.

Su, H., McCabe, M. F., Wood, E. F., Su, Z., and Prueger, J. H.: Modeling evapotranspiration during SMACEX: Comparing two approaches for local- and regional-scale prediction, J. Hydrometeorol., 6, 910-922, 2005.

$\mathrm{Su}, \mathrm{Z} .:$ The Surface Energy Balance System (SEBS) for estimation of turbulent heat fluxes, Hydrol. Earth Syst. Sci., 6, 85-100, doi:10.5194/hess-6-85-2002, 2002.

Sulkava, M., Luyssaert, S., Zhehle, S., and Papale, D.: Assessing and improving the representativeness of monitoring networks: The European flux tower network example, J. Geophys. Res., 116, G00J04, doi:10.1029/2010JG001562, 2011.

Tucker, C. J., Pinzon, J. E., Brown, M. E., Slayback, D. A., Pak, E. W., Mahoney, R., Vermote, E. F., and El Saleous, N.: An extended AVHRR 8-km NDVI dataset compatible with MODIS and SPOT vegetation NDVI data, Int. J. Remote Sens., 26, 44854498, 2005. van der Kwast, J., Timmermans, W., Gieske, A., Su, Z., Olioso, A., Jia, L., Elbers, J., Karssenberg, D., and de Jong, S.: Evaluation of the Surface Energy Balance System (SEBS) applied to ASTER imagery with flux-measurements at the SPARC 2004 site (Barrax, Spain), Hydrol. Earth Syst. Sci., 13, 1337-1347, doi:10.5194/hess-13-1337-2009, 2009.

Veenendaal, M., Kolle, O., and Lloyd, J.: Seasonal variation in energy fluxes and carbon dioxide exchange for a broad leaved semi-arid savanna (Mopane woodland) in Southern Africa, Glob. Change Biol., 10, 318-328, 2004.

Vinukollu, R. K., Sheffield, J., Wood, E. F., Bosilovich, M. G., and Mocko, D.: Multimodel Analysis of Energy and Water Fluxes: Intercomparisons between Operational Analyses, a Land Surface Model, and Remote Sensing, J. Hydrometeorol., 13, 3-26, 2011a.

Vinukollu, R. K., Wood, E. F., Ferguson, C. R., and Fisher, J. B.: Global estimates of evapotranspiration for climate studies using multi-sensor remote sensing data: Evaluation of three processbased approaches, Remote Sens. Environ., 115, 801-823, 2011 b.

Weligepolage, K., Gieske, A. S. M., van der Tol, C., Timmermans, J., and $\mathrm{Su}, \mathrm{Z}$.: Effect of sub-layer corrections on the roughness parameterization of a Douglas fir forest, Agr. Forest Meteorol., 162-163, 115-126, 2012.

Wharton, S., Schroeder, M., Paw U, K. T., Falk, M., and Bible, K.: Turbulence considerations for comparing ecosystem exchange over old-growth and clear-cut stands for limited fetch and complex canopy flow conditions, Agr. Forest Meteorol., 149, 14771490, 2009.

Wohl, E., Barros, A., Brunsell, N., Chappell, N. A., Coe, M., Giambelluca, T., Goldsmith, S., Harmon, R., Hendrickx, J. M. H., Juvik, J., McDonnell, J., and Ogden, F.: The hydrology of the humid tropics, Nature Clim. Change, 2, 655-662, 2012.

Yan, Y., Zhao, B., Chen, J., Guo, H., Gu, Y., Wu, Q., and Li, B.: Closing the carbon budget of estuarine wetlands with towerbased measurements and MODIS time series, Glob. Change Biol., 14, 1690-1702, 2008.

Yao, Y., Liang, S., Li, X., Hong, Y., Fisher, J. B., Zhang, N., Chen, J., Cheng, J., Zhao, S., and Zhang, X.: Bayesian multimodel estimation of global terrestrial latent heat flux from eddy covariance, meteorological, and satellite observations, J. Geophys. Res.-Atmos., 119, 4521-4545, 2014.

Zhu, Z., Bi, J., Pan, Y., Ganguly, S., Anav, A., Xu, L., Samanta, A., Piao, S., Nemani, R. R., and Myneni, R. B.: Global data sets of vegetation leaf area index (LAI) $3 \mathrm{~g}$ and Fraction of Photosynthetically Active Radiation (FPAR) $3 \mathrm{~g}$ derived from Global Inventory Modeling and Mapping Studies (GIMMS) Normalized Difference Vegetation Index (NDVI3g) for the period 1981 to 2011, Remote Sensing, 5, 927-948, 2013.

Zierl, B., Bugmann, H., and Tague, C. L.: Water and carbon fluxes of European ecosystems: An evaluation of the ecohydrological model RHESSys, Hydrol. Process., 21, 3328-3339, 2007. 